\title{
Drug Design for CNS Diseases: Polypharmacological Profiling of Compounds Using Cheminformatic, 3D-QSAR and Virtual Screening Methodologies
}

Katarina Nikolic ${ }^{1 *}$, Lazaros Mavridis ${ }^{2}$, Teodora Djikic $^{3}$, Jelica Vucicevic ${ }^{1}$, Danica Agbaba ${ }^{1}$, Kemal Yelekci ${ }^{3}$ and John B. O. Mitchell ${ }^{4}$

\begin{abstract}
${ }^{1}$ Department of Pharmaceutical Chemistry, Faculty of Pharmacy, University of Belgrade, Belgrade, Serbia, ${ }^{2}$ School of Biological and Chemical Sciences, Queen Mary University of London, London, UK, ${ }^{3}$ Department of Bioinformatics and Genetics, Faculty of Engineering and Natural Sciences, Kadir Has University, Istanbul, Turkey, ${ }^{4}$ EaStCHEM School of Chemistry and Biomedical Sciences Research Complex, University of St Andrews, St Andrews, UK
\end{abstract}

\section{HIGHLIGHTS}

- Many CNS targets are being explored for multi-target drug design

OPEN ACCESS

Edited by:

Rona R. Ramsay,

University of St Andrews, UK

Reviewed by:

Elizabeth Yuriev,

Monash University, Australia

Janez Mavri,

National Institute of Chemistry,

Slovenia

*Correspondence: Katarina Nikolic knikolic@pharmacy.bg.ac.rs

Specialty section:

This article was submitted to

Neuropharmacology,

a section of the journal

Frontiers in Neuroscience

Received: 22 March 2016 Accepted: 25 May 2016

Published: 10 June 2016

Citation:

Nikolic K, Mavridis L, Djikic T, Vucicevic J, Agbaba D, Yelekci K and Mitchell JBO (2016) Drug Design for CNS Diseases: Polypharmacological

Profiling of Compounds Using Cheminformatic, 3D-QSAR and Virtual

Screening Methodologies.

Front. Neurosci. 10:265

doi: 10.3389/fnins.2016.00265
- New databases and cheminformatic methods enable prediction of primary pharmaceutical target and off-targets of compounds

- QSAR, virtual screening and docking methods increase the potential of rational drug design

The diverse cerebral mechanisms implicated in Central Nervous System (CNS) diseases together with the heterogeneous and overlapping nature of phenotypes indicated that multitarget strategies may be appropriate for the improved treatment of complex brain diseases. Understanding how the neurotransmitter systems interact is also important in optimizing therapeutic strategies. Pharmacological intervention on one target will often influence another one, such as the well-established serotonin-dopamine interaction or the dopamine-glutamate interaction. It is now accepted that drug action can involve plural targets and that polypharmacological interaction with multiple targets, to address disease in more subtle and effective ways, is a key concept for development of novel drug candidates against complex CNS diseases. A multi-target therapeutic strategy for Alzheimer's disease resulted in the development of very effective Multi-Target Designed Ligands (MTDL) that act on both the cholinergic and monoaminergic systems, and also retard the progression of neurodegeneration by inhibiting amyloid aggregation. Many compounds already in databases have been investigated as ligands for multiple targets in drug-discovery programs. A probabilistic method, the ParzenRosenblatt Window approach, was used to build a "predictor" model using data collected from the ChEMBL database. The model can be used to predict both the primary pharmaceutical target and off-targets of a compound based on its structure. Several multi-target ligands were selected for further study, as compounds with possible additional beneficial pharmacological activities. Based on all these findings, 
it is concluded that multipotent ligands targeting AChE/MAO-A/MAO-B and also $D_{1}-R / D_{2}-R / 5-H T_{2 A}-R / H_{3}-R$ are promising novel drug candidates with improved efficacy and beneficial neuroleptic and procognitive activities in treatment of Alzheimer's and related neurodegenerative diseases. Structural information for drug targets permits docking and virtual screening and exploration of the molecular determinants of binding, hence facilitating the design of multi-targeted drugs. The crystal structures and models of enzymes of the monoaminergic and cholinergic systems have been used to investigate the structural origins of target selectivity and to identify molecular determinants, in order to design MTDLs.

Keywords: multi-target drugs, CNS disease, QSAR, rational drug design, cheminformatic, virtual screening, virtual docking

\section{POLYPHARMACOLOGY OF COMPOUNDS AGAINST CNS DISEASES}

Traditional drug discovery methods have mainly been based on development of selective agents for a specific target able to modulate its activity and the pathophysiology of the disease. This approach in now generally recognized as too simplistic for designing effective drugs to address complex multifactorial diseases, characterized by diverse physiological dysfunctions caused by dysregulation of complex networks of proteins (Anighoro et al., 2014). Modern drug design of multitarget ligands able to specifically modulate a network of interacting targets and show unique polypharmacological profiles is becoming increasingly important in drug discovery for multifactorial pathologies such as complex central nervous system (CNS) diseases (Hopkins, 2008; Mestres and GregoriPuigjaneİA, 2009; Boran and Iyengar, 2010; Peters, 2013; Anighoro et al., 2014).

The most significant advantages of the use of multitarget drugs over other therapeutic strategies, such as polypharmaceutical or single-targeted therapy, are: improved efficacy as result of synergistic or additive effects caused by simultaneous and specific interactions with chosen palette of biological targets; better distribution in target tissue for simultaneous action on multiple targets; accelerated therapeutic efficacy in terms of initial onset and achievement of full effect; treatment of broader therapeutic range of symptoms; predictable pharmacokinetic profile and mitigated drug-drug interactions; lower incidence of moleculebased side effects; increased therapeutic interval of doses as result of lower risk of acute and delayed toxicity; better quality of treatment; improved patient compliance and tolerance; and lower incidence of target-based resistance as result of modulation of multiple targets (Millan, 2006, 2014; Anighoro et al., 2014). The main challenge in drug discovery of MTDLs is to develop an efficient methodology for the design of novel multipotent

\footnotetext{
Abbreviations: MTDL, multi-target designed ligands; QSAR, quantitative structure-activity relationship; AD, Alzheimer's disease; PD, Parkinson's disease; AChE, acetylcholinesterase; BuChE, butyrylcholinesterase; MAO, monoamine oxidase; $A \beta$, amyloid beta; 5 -HT, serotonin receptor; D-R, dopamine receptor; $\mathrm{H}-\mathrm{R}$, histamine receptor, GPCRs, G protein-coupled receptors; HMT, histamine $\mathrm{N}$-methyltransferase; SERT, serotonin transporter; AMPK, 5' -adenosine monophosphate-activated protein kinase.
}

drugs able to interact only with one additional target and without significant affinities for other related targets.

The polypharmacological design of CNS drugs is challenging because of the complex pathophysiological mechanisms of brain diseases, interactions of neurotransmitter systems and observed ligand cross-reactivities (Roth et al., 2004). Since multipotent ligands could also interact with off-targets and cause targetbased adverse effects, a major objective in polypharmacology is to rationally design multi-target drugs able to specifically modulate only a group of desired targets while minimizing interactions with off-targets and avoiding interactions with anti-targets (Anighoro et al., 2014; Millan, 2014). Multi-Target Designed Ligands (MTDL) contain the primary pharmacophore elements for each target which could be separated by a linker (conjugate MTDLs), could touch at one point (fused), or could be combined by using commonalities in the structures of underlying pharmacophores (merged) (Besnard et al., 2012; Millan, 2014).

Smaller and relatively rigid structures of highly merged MTDLs result in better physicochemical, pharmacokinetic and pharmacological profiles (Besnard et al., 2012; Millan, 2014). For the rationally designed MTDLs, activities against the targets and pharmacokinetic profiles are predicted. Based on the results obtained, the most promising MTDLs are selected for further modifications and studies (Hajjo et al., 2010; Besnard et al., 2012; Hajjo et al., 2012; Zhang et al., 2013; Nikolic et al., 2015a).

Several previous studies confirmed that multifactorial pathologies, such as cerebral mechanisms implicated in neurological and psychiatric diseases (Threlfell et al., 2004; Dai et al., 2007; Garduno-Torres et al., 2007; Humbert-Claude et al., 2007; Gemkow et al., 2009) and neurodegenerative disorders (Goedert and Spillantini, 2006), are often polygenic and involve the dysregulation of very complex networks of proteins. The diverse cerebral mechanisms implicated in CNS diseases together with the heterogeneous and overlapping nature of phenotypes indicated that multitarget strategies may be appropriate for improved treatment of complex brain diseases. Both the activity and the side effects of CNS drugs are characterized by a complex pattern of biological activities on multiple targets and a complex mechanism of action (Roth et al., 2004; Lipina et al., 2012, 2013). Understanding how the neurotransmitter systems interact is also important in optimizing therapeutic strategies. Pharmacological intervention on the dopamine system will often influence the 
serotonin or glutamate neurotransmitter systems. Interactions of the neurotransmitter systems, such as the dopamine-glutamate interaction (Carlsson and Carlsson, 1990; Millan, 2005) and the serotonin-dopamine interaction (Di Giovanni et al., 2008; Di Matteo et al., 2008), are also very important factors in design of multitargeted ligands with specific cross-reactivity and optimized neuropharmacological effects (Youdim and Buccafusco, 2005). Therefore, a more efficient polypharmacological strategy for treatment of complex CNS diseases is based on drug interactions with multiple targets, to address disease in more subtle and effective ways while avoiding side effects arising from interaction with defined antitargets and off-targets (Lu et al., 2012; Anighoro et al., 2014). Thus, polypharmacology is now recognized as a key pharmacological concept for development of novel drug candidates against complex CNS diseases.

As a result of the multitarget approach (Morphy and Rankovic, 2005; León et al., 2013; Anighoro et al., 2014; Millan, 2014) many CNS drugs with improved efficacy compared to their lead compounds have been developed and examined. Monoamine reuptake inhibitors with serotonin 5$\mathrm{HT}_{2 \mathrm{C}}$ antagonistic properties were developed as novel class of antidepressants (Millan, 2006; Meltzer et al., 2012; Quesseveur et al., 2012). Dopamine receptors are G protein-coupled receptors (GPCRs), distinct in pharmacology, amino acid sequence, distribution, and physiological function. Based on their effector-coupling profiles dopamine receptors are organized into two families, the $\mathrm{D}_{1}$-like $\left(\mathrm{D}_{1}, \mathrm{D}_{5}\right)$ and $\mathrm{D}_{2}$-like $\left(\mathrm{D}_{2}, \mathrm{D}_{3}, \mathrm{D}_{4}\right)$ receptors (Brunton et al., 2011).

The physiological processes under dopaminergic control include reward, emotion, cognition, memory, and motor activity. Therefore, dysregulation of the dopaminergic system is critical in a number of disease states, including Parkinson's disease, Tourette's syndrome, bipolar depression, schizophrenia, attention deficit hyperactivity disorder, and addiction/substance abuse (Brunton et al., 2011). Dopamine receptor antagonists are a mainstay in the pharmacotherapy of schizophrenia.

Since the pathophysiology of schizophrenia and related diseases involves deregulation of the dopamine, serotonin and glutamate neurotransmitter systems (Witkin and Nelson, 2004; Esbenshade et al., 2008; Brunton et al., 2011), therapeutic effects of typical and atypical neuroleptics are mostly mediated by inhibition of dopamine $\mathrm{D}_{1} / \mathrm{D}_{2}$-like receptors and other related aminergic receptors (Table $\mathbf{1}$ ). Blockade of dopamine $\mathrm{D}_{2}$ and serotonin $5-\mathrm{HT}_{2 \mathrm{~A}}$ receptors is the main mechanism of action of atypical antipsychotics (Remington, 2003). Furthermore, interaction with various dopamine $\left(\mathrm{D}_{1}, \mathrm{D}_{3}, \mathrm{D}_{4}\right)$, serotonin $\left(5-\mathrm{HT}_{1 \mathrm{~A}}, 5-\mathrm{HT}_{1 \mathrm{D}}, 5-\mathrm{HT}_{2 \mathrm{~A}}, 5-\mathrm{HT}_{2} \mathrm{C}, 5-\mathrm{HT}_{6}\right.$, and $\left.5-\mathrm{HT}_{7}\right)$, and histamine $\mathrm{H}_{3}$ receptors may produce additional antipsychotic or procognitive effects (Reynolds, 2004; Esbenshade et al., 2008; Coburg et al., 2009) by indirectly modulating the mesolimbic dopaminergic neurons (Amato, 2015).

A significant improvement in schizophrenia therapy came in the early 2000s with the use of aripiprazole acting as a dopamine $\mathrm{D}_{2}$-like partial agonist with partial agonistic properties on serotonergic $5-\mathrm{HT}_{1 \mathrm{~A}}$ and $5-\mathrm{HT}_{2 \mathrm{~A}}$ receptors (Buckley, 2003; Kiss et al., 2010; Johnson et al., 2011). Dopamine $\mathrm{D}_{2} / \mathrm{D}_{3}$ antagonists, with $5-\mathrm{HT}_{2 \mathrm{~A}}$ antagonistic and $5-\mathrm{HT}_{1 \mathrm{~A}}$ partial agonistic activities, were proposed as drug candidates for schizophrenia therapy (Roth et al., 2004; Lipina et al., 2012, 2013). The efficient polypharmacological profile of aripiprazole and related antipsychotics resulted in the development of cariprazine and pardoprunox as drug candidates, which are currently in clinical trials (Ye et al., 2014).

Despite selective $\mathrm{D}_{1}$ antagonism not being accepted on its own as an effective antipsychotic principle (Table 1; Tauscher et al., 2004; Sedvall and Karlsson, 2006), moderate antagonistic activity at $\mathrm{D}_{1}$-receptors has been confirmed to be responsible for atypical neuroleptic clozapine effectiveness against treatmentresistant schizophrenia (Tauscher et al., 2004). Based on the polypharmacological profiles of recently approved antipsychotic drugs, it could be concluded that optimal and balanced modulation of $D_{1} / D_{2}$-like receptors - as well as interaction with serotonin and histamine $\mathrm{H}_{3}$ receptors - should provide the most favorable neuroleptic effect. The successfully developed effective MTDLs with optimal polypharmacological profile for CNS diseases (Table 1) are experimental proof of the polypharmacological concept. Polypharmacological approaches are therefore likely to be extensively applied for rational design of ligands with optimal multitarget profile and for discovery of multipotent drug candidates with improved efficacy and safety in therapy of complex brain diseases.

Novel procognitive agents were developed as histamine $\mathrm{H}_{3} \mathrm{R}$ antagonists/inverse agonists with inhibition of acetylcholine esterase (AChE), monoamine oxidase (MAO), histamine $\mathrm{N}$ methyltransferase (HMT), or serotonin transporter (SERT) (Ligneau et al., 1998; Apelt et al., 2002, 2005; Grassmann et al., 2003, 2004; Petroianu et al., 2006; Decker, 2007; Esbenshade et al., 2008; Sander et al., 2008; Coburg et al., 2009; Bajda et al., 2011; Nikolic et al., 2015a). Rasagiline and ladostigil, drugs currently used as selective MAO-B inhibitors in therapy of PD, contain the propargylamine scaffold and therefore exert significant neuroprotective activity. Thus, phase II clinical trials of rasagiline (www.clinicaltrials.gov/ct2/show/NCT00104273) and ladostidil (www. clinicaltrials.gov/ct2/show/NCT01354691) in therapy of AD were proposed, and subsequently successfully completed. A multi-target therapeutic strategy for Alzheimer's disease resulted in the development of very effective MTDLs that act on both the cholinergic and monoaminergic systems, and also retard the neurodegenerative progress by inhibiting amyloid aggregation. Multi-target inhibitors of acetylcholine esterase and MAO (AChE/BuChE/MAO-A/MAO-B) were effective drug candidates for therapy of neurodegenerative Alzheimer's (AD) and Parkinson's diseases (PD) (Pérez et al., 1999; MarcoContelles et al., 2006, 2009; Bolea et al., 2011; León et al., 2013; Bautista-Aguilera et al., 2014a,c; Nikolic et al., 2015b).

Besides the difficulties of effective modulation of the CNS targets, the need to design drugs that are able to reach the targets in the brain increases the complexity of CNS drug discovery. This is mainly due to the blood-brain barrier (BBB) protection system between the blood capillaries of the brain and brain tissue (Pardridge, 2005). The BBB enables selective access of required nutrients and hormones, while removing waste and preventing or reducing penetration of xenobiotics (Pardridge, 2005). Therefore, a major challenge in CNS drug discovery is to build and apply relationships between chemical structure and brain exposure (Rankovic and Bingham, 2013; Rankovic, 
TABLE 1 | Polypharmacological profiles of drugs and drug candidates affecting the dopaminergic system.

\section{Compound}

Targets

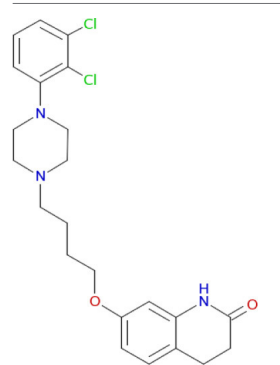

Aripiprazole (Johnson et al., 2011)

$D_{2}, D_{3}, 5-H T_{2 B}, D_{4}, 5-H T_{2 A}, 5-H T_{1 A}, 5-H T_{7}, \alpha_{1 A}, H_{1}$ receptors (Buckley, 2003; Shapiro et al., 2003)<smiles>CN(C)CCC=C1c2ccccc2CCc2ccccc21</smiles>

Amitriptyline (Coburg et al., 2009)

$D_{1}, D_{5}, D_{2}, D_{3}, H_{1}$ receptors (Ligneau et al., 2000)

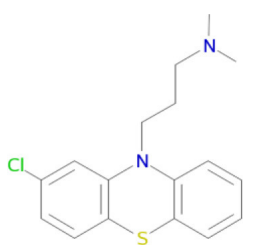

Chlorpromazine (Bourne, 2001)

$D_{1}, D_{5}, D_{2}, D_{3}, D_{4}, 5-H T_{2 a}$ receptors (Rajagopalan et al., 2014)

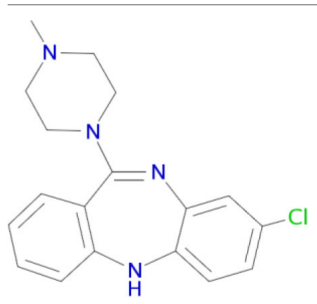

Clozapine (Coburg et al., 2009)

$D_{1}, D_{5}, D_{2}, D_{3}, D_{4}, 5-H T_{2 A}, H_{1}$ receptors (Ligneau et al., 2000; Bourne, 2001; Rajagopalan et al., 2014)<smiles>CN(C)CCC=C1c2ccccc2Sc2ccc(Cl)cc21</smiles>

Chlorprothixene (Coburg et al., 2009)

$D_{1}, D_{5}, D_{2}, D_{3}, D_{4}, H_{1}$ receptors (Ligneau et al., 2000)<smiles>OCCN1CCN(CCCN2c3ccccc3Sc3ccc(C(F)(F)F)cc32)CC1</smiles>

Fluphenazine (Coburg et al., 2009)

$D_{1}, D_{5}, D_{2}, D_{3}, D_{4}, H_{1}$ receptors (Ligneau et al., 2000)

(Continued) 


Compound Targets
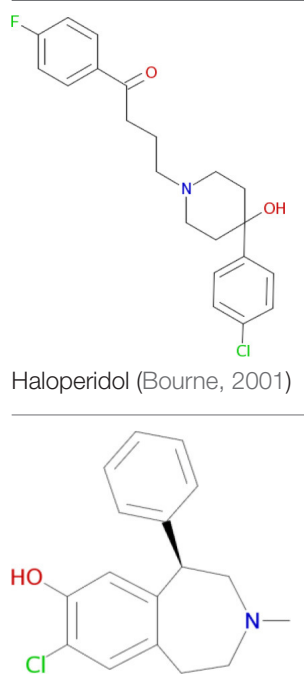

SCH 23390 (Bourne, 2001)

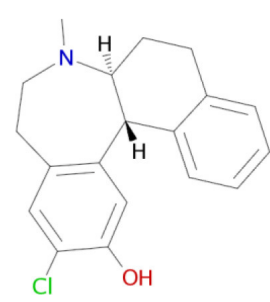<smiles></smiles>

13 (Coburg et al., 2009)
$D_{1}, D_{5}, D_{2}, D_{3}, D_{4}, H_{1}, H_{3}$ receptors (Ligneau et al., 2000; Bourne, 2001; Hamacher et al., 2006; Rajagopalan et al., 2014) 2015a). Total brain concentration $(\mathrm{Cb})$ is now recognized as being only a portion of the non-specific binding to brain tissue, while the unbound brain concentration $(\mathrm{Cu}, \mathrm{b})$ is defined as the drug concentration at the target sites and is a measure of in vivo drug efficacy. Finally, receptor occupancy (RO) is direct measure of target engagement (Rankovic, 2015b). Lipophilicity of CNS drugs is generally considered the most critical physicochemical parameter for improved penetration and potency. Higher lipophilicity causes low solubility, high plasma protein binding, and increased metabolic and toxicity risks in CNS drugs (Leeson and Springthorpe, 2007). Furthermore, hydrogen bond molecular parameters are the dominant descriptors for unbound drug brain concentrations (Leeson and Davis, 2004). Reducing the HBD (Hydrogen Bond Donor) count of a molecule is one of the most successful strategies used in the optimization of brain exposure (Weiss et al., 2012). In CNS drug discovery, aqueous solubility is also considered in combination with the previously described parameters. Most of the CNS drugs with low safety risk are very soluble compounds, displaying aqueous solubility of more than $100 \mu \mathrm{M}$ (Alelyunas et al., 2010). Generally, fine-tuning physicochemical properties for optimal brain exposure is now an essential method in CNS drug discovery (Table 2). Further studies of CNS property space and development of predictive models for brain exposure should result in the formation of a general methodology with a wide applicability domain in CNS drug design.

\section{D-QSAR STUDY OF MULTITARGET COMPOUNDS FOR CNS DISEASES}

QSAR (Quantitative Structure-Activity Relationship) modeling has progressed from analysis of small series of congeners using 
TABLE 2 | Developing CNS property space for optimal brain exposure (Rankovic and Bingham, 2013; Rankovic, 2015b).

CNS property space

TPSA $<60 \AA^{2}, p K a<8$ and HBD count $<2$ are minimizing P-gp recognition (Hitchcock, 2012; Desai et al., 2013)

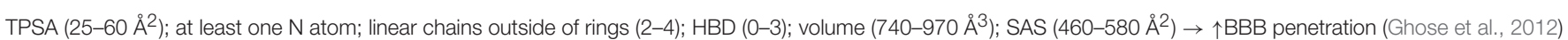

Optimal CLogP <3 (Gleeson, 2008)

CLogP $<4$ and TPSA 40-80 $\AA^{2} \rightarrow \uparrow C u$,b (Raub et al., 2006)

$\mathrm{PSA}<90 \AA^{2} ; \mathrm{HBD}<3$; cLogP 2-5; CLogD (pH 7.4) 2-5; and MW < $500 \rightarrow \uparrow B B B$ penetration (Hitchcock and Pennington, 2006)

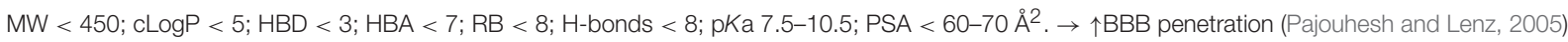

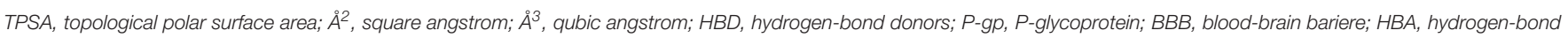

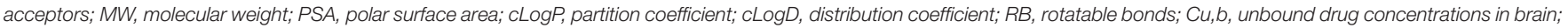
$\downarrow$, decreased; $\uparrow$, increased.

basic regressions to applications on very large and diverse data sets using a variety of statistical and machine learning methods. Today's QSAR practice widely uses ligand based theoretical approaches for modeling the physical, biological and pharmacological properties of compounds, and forms a crucial initial step in drug discovery. Together with structure-based methods, statistically based QSAR techniques are essential tools in lead optimization within several leading drug discovery groups (Cramer, 2012; Cherkasov et al., 2014).

Modern QSAR methodologies started with a 1962 publication by the Hansch group (Hansch et al., 1962), and further developed with the exploration of series of congeners (Craig, 1971; Topliss, 1972; Hansch et al., 1973). Steric effects of substituents were successfully described by five shape descriptors for substituents (Verloop et al., 1976). Electrostatic interaction energies in a series of superimposed 3D-conformations of analogs were effectively included in CoMFA (Comparative Molecular Field Analysis) and other 3D-QSAR methods (Cramer et al., 1988). In CoMFA, steric and electrostatic molecular fields of ligands are calculated and correlated with bioactivities by use of PLS (Partial Least Squares) (Wold et al., 1984). Based on the CoMFA approach, the CoMSIA method (Molecular Similarity Indices in a Comparative Analysis) was developed (Klebe et al., 1994), encompassing the steric, electrostatic, hydrogen bonding and hydrophobic effects of ligands. The main limitation of CoMFA/CoMSIA and other 3D-QSAR methods relates to their being applicable only to static structures of chemical analogs, while neglecting the dynamical nature of the ligands (Acharya et al., 2011).

Molecular field generating software, such as GRID (Goodford, 1985) and PHASE (Dixon et al., 2006), historically applied pharmacophoric constraints to facilitate 3D-QSAR modeling, considering multiple conformations. The new generation of 3D-descriptors, such as GRIND/GRIND-2/GRID-PP (GridIndependent Descriptor), are alignment free descriptors derived from the Molecular Interaction Fields (MIF) of the series and designed to retain the chemical characteristics of the ligands examined. The GRIND descriptors so obtained are provided by programs from Molecular Discovery (Pastor et al., 2000; Durán et al., 2009) and used for advanced multivariate analyses and 3D-QSAR modeling.
Some novel 3D-QSAR approaches based on ligand-based 3D-QSAR models and complementary drug target fields are included in the AFMoC (Gohlke and Klebe, 2002) and QMOD (Varela et al., 2012) programs. The QSAR study of multitarget compounds involves QSAR modeling for each target activity individually, study of all developed QSAR models as part in a network of interrelated models, and design of novel multipotent compounds (Cherkasov et al., 2014). Combinations of the QSAR approach and related theoretical methods, such as virtual screening and docking, are very useful in the study and design of multitarget ligands with unique polypharmacological profiles (Figure 1; Ning et al., 2009; Zheng et al., 2010; Besnard et al., 2012; Kupershmidt et al., 2012; Bolea et al., 2013; BautistaAguilera et al., 2014c). Based on the developed QSAR models, analogs of a multitarget lead are designed with enhanced activity on the targets and optimal polypharmacological and safety profiles as drug candidates for further study. Recently developed QSAR approaches were the only in silico methodologyies able to distinguish between antagonists and agonists of olfactory receptors (ORs), a superfamily of G-protein coupled receptors (Don and Riniker, 2014).

Several successful cases of reported 3D-QSAR studies used in CNS drugs discovery have been listed in Table 3. In this chapter we provide an overview of some of them. For example, polypharmacological profiles of in silico generated analogs of donepezil, an approved acetylcholinesterase inhibitor drug, were evaluated by a QSAR study. More than $75 \%$ of the ligand-target predictions were confirmed by in vitro testing (Besnard et al., 2012). Pathophysiology of Alzheimer's disease $(\mathrm{AD})$ includes extracellular deposition of amyloid $\beta$ peptide $(\mathrm{A} \beta)$-containing plaques, progressive loss of cholinergic neurons, metal dyshomeostasis, mitochondrial dysfunction, neuroinflammation, oxidative stress and increased MAO enzyme activity. Furthermore, levels of neurotransmitters such as dopamine, noradrenaline, and serotonin are significantly decreased in AD patients (Reinikainen et al., 1990). MAO-A/B inhibitors could increase the levels of dopamine, noradrenaline, and serotonin in the CNS. Therefore, MAO-A/B inhibitors have also been proposed as potential drugs for $\mathrm{AD}$ (Youdim et al., 2006). 


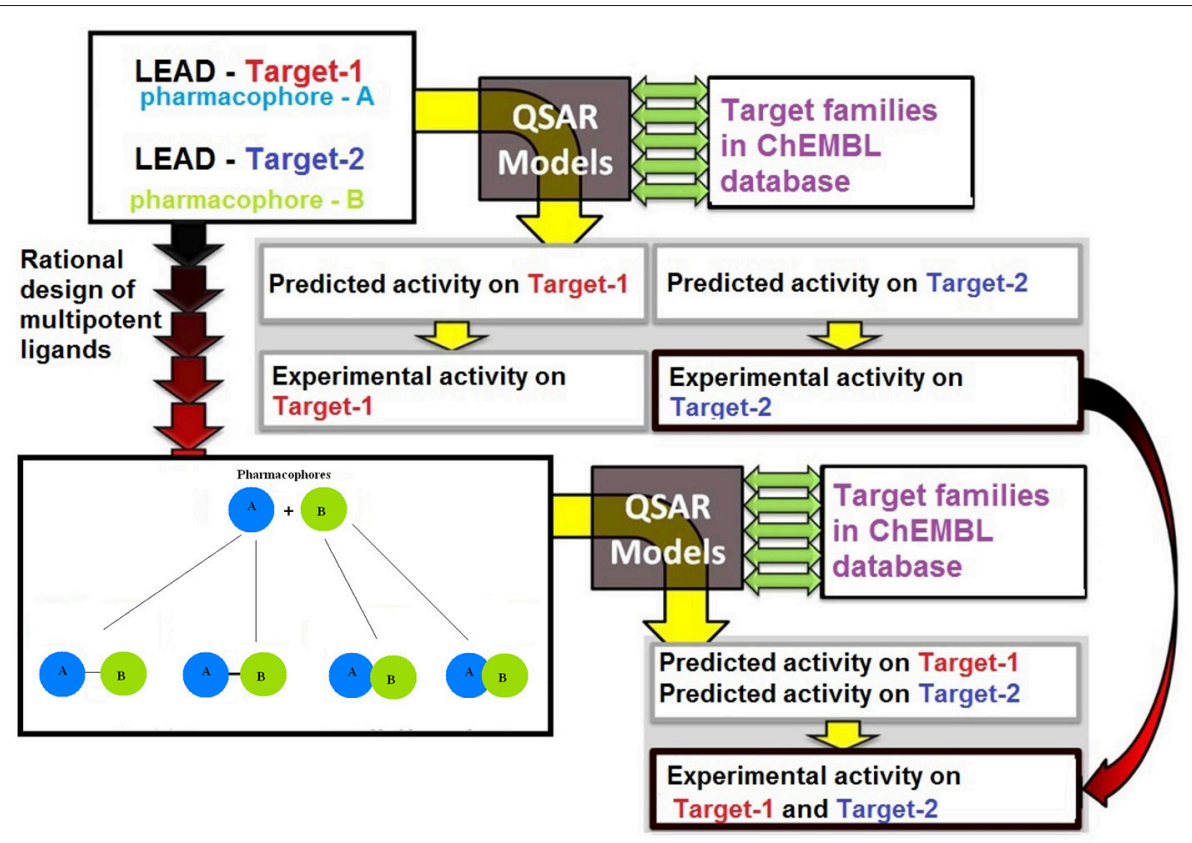

FIGURE 1 | Computer-aided rational design of multipotent ligands with controlled polypharmacology.

TABLE 3 | Reported 3D-QSAR studies used in CNS drug discovery.

\begin{tabular}{|c|c|c|c|c|}
\hline Drug target & CNS disease & 3D-QSAR method & Software package & References \\
\hline AChE & $A D$ & $\begin{array}{l}\text { Molecular field based 3D-QSAR } \\
\text { modeling (Dixon et al., 2006) }\end{array}$ & PHASE www.schrodinger.com & $\begin{array}{l}\text { Lakshmi et al., } \\
2013\end{array}$ \\
\hline AChE, BuChE & $A D$ & $\begin{array}{l}\text { CoMFA based 3D-QSAR modeling } \\
\text { Wold et al. (1984) }\end{array}$ & Tripos Sybyl www.tripos.com & Li et al., 2013 \\
\hline $\begin{array}{l}\mathrm{H}_{3}-\mathrm{R}, \mathrm{HMT}, \mathrm{AChE} \\
\text { BuChE }\end{array}$ & $\begin{array}{l}\text { AD, PD, } \\
\text { depression, } \\
\text { schizophrenia }\end{array}$ & $\begin{array}{l}\text { Molecular field and GRID based } \\
\text { 3D-QSAR modeling (Goodford, 1985; } \\
\text { Pastor et al., 2000; Dixon et al., 2006; } \\
\text { Durán et al., 2009) }\end{array}$ & $\begin{array}{l}\text { PHASE www.schrodinger.com Pentacle } \\
\text { www.moldiscovery.com }\end{array}$ & $\begin{array}{l}\text { Nikolic et al., } \\
2015 a\end{array}$ \\
\hline
\end{tabular}

Multimodal brain permeable drugs affecting a few brain targets involved in the disease pathology, such as MAO and ChE enzymes, iron accumulation and amyloid- $\beta$ generation/aggregation, were extensively examined as an essential therapeutic approach in $\mathrm{AD}$ treatment (Zheng et al., 2010; Bautista-Aguilera et al., 2014b). For instance, hybrid compound M30D contains the important pharmacophores from three drugs: tacrine, rivastigmine (ChEIs) and rasagiline/ladostigil (MAO-B inhibitor) (Zheng et al., 2010), while ASS234 and MBA236 contain the pharmacophores of the drugs donepezil (ChEIs) and clorgiline (MAO-A inhibitor) (Bolea et al., 2011). Pharmacophore and 3D-QSAR studies of donepezil and clorgiline derivatives inhibiting both $\mathrm{AChE} / \mathrm{BuChE}$ and MAO-A/B were successfully applied for lead optimization work and for design of ASS234, MBA236 and related ligands with optimal polypharmacological and pharmacokinetic profiles (Bautista-Aguilera et al., 2014a,b,c). The propargylamine moiety in the MAOinhibiting pharmacophore of rasagiline, ladostigil or clorgiline is responsible for their neuroprotective-neurorestorative effects. Therefore, the propargylamine moiety was used as the main chemical scaffold responsible for MAO inhibition in the designed M30D, ASS234, and MBA236 hybrids (Figure 2). Hybrid compound ASS234 acted as an 11-fold less potent MAO-A inhibitor and 54-fold more potent MAO-B inhibitor than the reference compound clorgiline, while MBA236 was nine times more potent as an MAO-A inhibitor and 6-fold more potent for MAO-B than reference compound ASS234. Inhibition of the ChEs by the hybrid MBA236 is in the micromolar range, slightly better than compound ASS234 for AChEs while slightly 
poorer for BuChE (Table 4; Bautista-Aguilera et al., 2014b). The Multi-Target Designed Ligand M30D was found to be a highly potent inhibitor of MAO-A with moderate MAO-B inhibiting activity. Also, M30D was a more potent AChE inhibitor than rivastigmine, while rivastigmine was a much stronger $\mathrm{BuChE}$ inhibitor than M30D (Table 4; Zheng et al., 2010). Further to their MAO/ChE inhibitory properties, ASS234 and M30D exert beneficial pharmacological effects in therapy of $\mathrm{AD}$ by inhibiting $\mathrm{A} \beta$ plaque formation and aggregation and, by blocking AChEmediated $A \beta 1-40 / A \beta 1-42$ aggregation (Kupershmidt et al., 2012; Bolea et al., 2013).

\section{CHEMINFORMATICS METHODS FOR ON-TARGET AND OFF-TARGET BIOACTIVITY PREDICTION}

The prediction of interactions between druglike organic molecules and proteins is a ubiquitous goal at the interface of biology and chemistry. The problem is approached from various different directions and with diverse purposes in mind. Much of this section will discuss the use of cheminformatics

TABLE 4 | IC50 values for the inhibitory effects of test compounds on the enzymatic activity of MAO-A, MAO-B, AChE, and BuChE.

\begin{tabular}{lcccc}
\hline Compound & MAO-A & MAO-B & AChE & BuChE \\
\hline MBA236 $^{\mathrm{a}}$ & $6.3 \pm 0.4 \mathrm{nM}$ & $183.6 \pm 7.4 \mathrm{nM}$ & $2.8 \pm 0.1 \mu \mathrm{M}$ & $4.9 \pm 0.2 \mu \mathrm{M}$ \\
ASS234 $^{\mathrm{a}}$ & $58.2 \pm 1.2 \mathrm{nM}$ & $1.2 \pm 0.1 \mu \mathrm{M}$ & $3.4 \pm 0.2 \mu \mathrm{M}$ & $3.3 \pm 0.2 \mu \mathrm{M}$ \\
Clorgiline $^{\mathrm{a}}$ & $4.7 \pm 0.2 \mathrm{nM}$ & $65.8 \pm 1.6 \mu \mathrm{M}$ & $* *$ & $* *$ \\
M30D $^{\mathrm{b}}$ & $7.7 \pm 0.7 \mathrm{nM}$ & $7.9 \pm 1.3 \mu \mathrm{M}$ & $0.5 \pm 0.1 \mu \mathrm{M}$ & $44.9 \pm 6.1 \mu \mathrm{M}$
\end{tabular}

a Bautista-Aguilera et al. (2014b).

b Zheng et al. (2010).

**Inactive at $100 \mu \mathrm{M}$ (highest concentration tested). methods to identify likely interactions between ligands, as the organic molecules are collectively called, and proteins. Such predictions may have many uses in terms of understanding the likely bioactivities of molecules and both cellular and molecular functions of proteins.

The prediction of pharmaceutically relevant molecular properties has been the default problem addressed by cheminformatics throughout its history. The most obvious application, and a useful source of financial support, for cheminformatics research has been drug discovery. The label "drug discovery," however, obscures the complexity of a variety of distinct questions. One objective, early in the drug discovery pipeline, is the identification of lead compounds, molecules possessing modest pharmacological activity that are starting points for chemical modifications enhancing their potency, selectivity and bioavailability. Subsequently, lead optimization will require Quantitative Structure-Activity Relationship (QSAR) studies to understand which modifications will best enhance affinity while, for instance, maximizing solubility and avoiding regions of chemical space likely to lead to toxicity.

Protein target predictions (Bender et al., 2007; Lounkine et al., 2012) allow us to link molecular interactions to biological effects, and hence to identify and rationalize the bioactivities of compounds. Since many molecules interact promiscuously with several targets as well as different ligands interacting with the same target (Figure 3), we must predict off-target as well as on-target interactions. Protein-ligand interactions, other than those with the expected pharmacological protein target, can help to identify opportunities for drug repurposing (Kinnings et al., 2011; Napolitano et al., 2013), where a drug developed for one disease is able to treat a different condition. Such compounds have the advantage of already having been optimized for bioavailability and non-toxicity. More adventurously, polypharmacology (Chen et al., 2009) is possible, where deliberate use is made of the drug's ability to hit two targets,

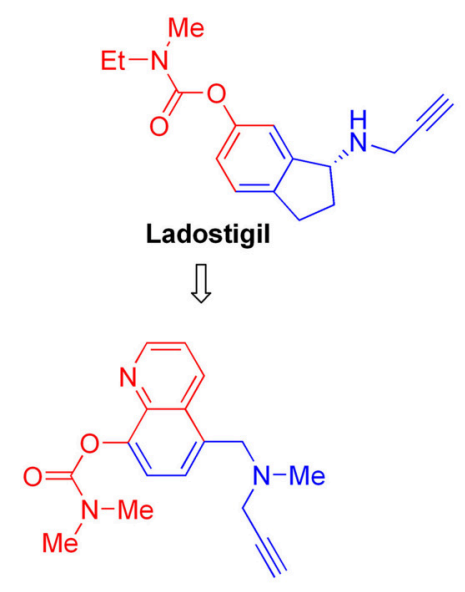

M30D

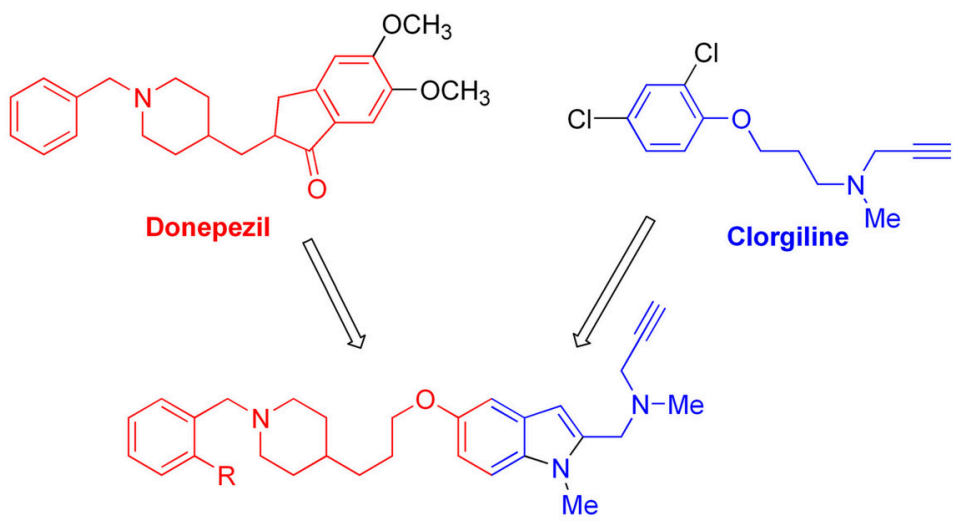

MBA236 $(\mathrm{R}=\mathrm{Me}) \quad$ ASS234 $(\mathrm{R}=\mathrm{H})$

FIGURE 2 | Structures and pharmacophores of effective Multi-Target Designed Ligands against AD. Blue coloring represents the MAO inhibitor pharmacophore and red represents the ChE inhibitor pharmacophore. 


\section{Promiscuous Ligand}

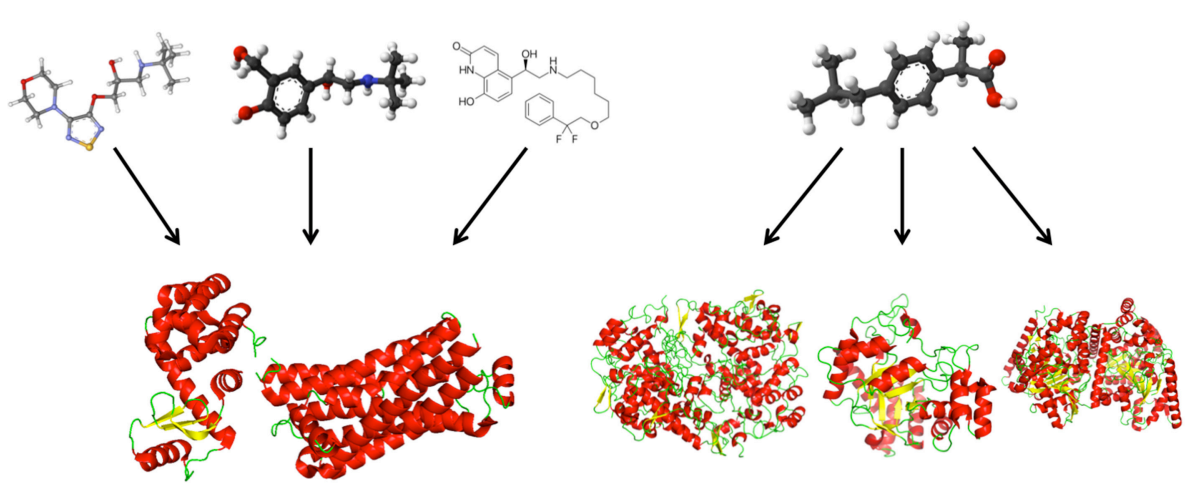

Promiscuous Target

FIGURE 3 | Illustrations of the cases of a promiscuous ligand and a promiscuous target (left and right, respectively).

permitting more subtle modulation of its effect on a disease. Just as importantly, off-target prediction can identify likely sideeffects (Lounkine et al., 2012) and adverse drug reactions (Bender et al., 2007).

\section{Similarity-Based Methods}

One of the core methodologies of cheminformatics is the use of molecular similarity to predict bioactivity. In the simplest singletarget cases, an in silico library of chemical structures is compared with those chemical structures known to possess bioactivity against that protein. Molecules are usually represented by one of the many sets of fingerprints or descriptors (Steinbeck et al., 2003; Bender et al., 2004) that distil various chemical, topological and physicochemical properties of a molecular structure into a string of tens to hundreds of bits. This exercise is predicated on the Similar Property Principle, that structures close together in the vector space defined by the descriptors should possess similar chemical or biochemical properties. Thus, proximity in an arbitrary chemical space is used as a proxy for likely similarity of properties. This is an extremely common approach for lead identification.

\section{Adaptation of Similarity Approaches to Off-Target Prediction}

We have created our own similarity-based procedure that has two significant modifications and is particularly suitable for use on multi-target problems with some missing data. This workflow has been applied in our work to two specific problems: the identification of performance-enhancing molecules that should be prohibited in sports (Mavridis and Mitchell, 2013), and predicting multi-target bioactivities of potential polypharmacological compounds for treatment of neurological diseases (Nikolic et al., 2015b).

The first methodological modification is that we do not base our search on single known actives, but rather on families of compounds. We define our families on the twin criteria of bioactivity against a particular protein family and cluster membership (Mavridis et al., 2013) of structurally similar ligands. For each target, we obtain one or often more refined families, as we call them, of compounds sharing both a structural scaffold and a target-specific bioactivity in common.

Our second modification was to devise a quantitative method of estimating the probability that a given query molecule is associated with a particular bioactivity-scaffold combination defining one specific refined family. This allows us to make comparable predictions across both on-target and off-target activities based on the current 1,715,667 compounds and 10,774 targets in the ChEMBL database (Gaulton et al., 2012). Doing this requires us to create a common scale for the different affinity measures reported in the literature, (IC50, Ki, Kd, EC50, ED50, potency, activity, inhibition) relevant to bioactivity. We applied a number of rules in order to generate sets of molecules experimentally reported to be bioactive, given affinities defined using the eight different measures, separating these from sets of inactive molecules. Those empirical rules were derived by considering the distributions of the different affinity measures amongst reported active and inactive compounds. Subsequently, we use the Parzen-Rosenblatt (PR) (Rosenblatt, 1956; Parzen, 1962) kernel density estimation method to transform Tanimoto similarities into probabilities of family membership.

Our study of molecules related to doping in sport (Steinbeck et al., 2003) used protein target prediction to predict athletic performance-enhancing properties. In it, we demonstrated that the freely available ChEMBL database can be clustered into bioactivity-based refined families of ligands, using our clustering algorithm PFClust (Mavridis and Mitchell, 2013). These refined families consist of distinct sets of compounds, each set with its own molecular scaffold. For example, we separated the ligands for the beta-2 adrenergic receptor, a target hit by many beta blockers, into two distinct families with each ligand generating a high probability of belonging to just one or other of the two groups and a lower score for the alternative refined family, as 
shown in Figure 4. The use of such structurally distinct refined families significantly improved our method's performance in cross-validation, to the extent of giving encouraging concordance with experiment. Overall, two thirds of our test cases in crossvalidation had the correct refined family as the number one prediction, and seven eighths had this "correct" family among the top four hits. We sometimes found many different scaffolds for one target; for the androgen receptor ligands PFClust generated 126 different refined families. Even where we have no experimental data, we can still undertake predictions of the likely bioactivity. We identified the protein targets corresponding to seven of the World Anti-Doping Agency's defined prohibited classes of compounds; we found a mixture of expected and surprising protein targets. Many of the apparently unexpected targets, however, turned out to have published biochemically or clinically validated links to the relevant bioactivities.

We recently studied (Nikolic et al., 2015b) multi-target ligands intended to interact with MAO A and B; acetylcholinesterase (AChE) and butyrylcholinesterase (BuChE); or with histamine $\mathrm{N}$-methyltransferase (HMT) and histamine $\mathrm{H} 3$-receptor $\left(\mathrm{H}_{3} \mathrm{R}\right)$. These enzymes are all potential drug targets for neurological conditions, including depression, Alzheimer's disease, obsessive disorders, and Parkinson's disease. Three groups of dual or multi-target compounds facilitated the generation of 3DQSAR models for activity against the aforementioned protein targets. The first set of ligands consisted of novel carbonitrileaminoheterocyclic compounds, designed to inhibit both MAO $\mathrm{A}$ and $\mathrm{B}$. Amongst these, dicarbonitrile aminofuran derivatives were generally more selective MAO A inhibitors. The second group included acetylene-, indol-, piperidine- and pyridinederivatives, which exhibited polypharmacology against MAO $\mathrm{A} / \mathrm{B}, \mathrm{AChE}$, and $\mathrm{BuChE}$. These agents are putative multitarget compounds against Alzheimer's disease. The third set of ligands contained multipotent histamine H3R antagonists that can concurrently inhibit HMT, and are therefore two-target procognitive compounds with potential therapeutic application against several psychiatric and neurodegenerative diseases. We used the Parzen-Rosenblatt kernel approach to build probabilistic models for both primary targets and off-targets, using data collected from the ChEMBL (Nikolic et al., 2015b) and DrugBank (Knox et al., 2011) databases. The cheminformaticsbased target identifications agreed with four 3D-QSAR models for the various receptors, and with in vitro assays for serotonin 5 $\mathrm{HT}_{1 \mathrm{~A}}$ and $5 \mathrm{HT}_{2 \mathrm{~A}}$ receptor binding of the most promising ligand. As a result of this work, this and several other multi-target ligands were chosen for further investigation of their possible additional beneficial pharmacological activities.

Ain et al. (2014) used both protein and ligand descriptors to model the multi-target inhibitory profiles of serine proteinase inhibitors. They built separate sets of Random Forest (Breiman, 2001) models, some using only ligand descriptors, which they called "QSAR models," and others built using also protein descriptors, namely "proteochemometric (PCM) models". Across 12,625 inhibitors and 67 targets, they found that the models including protein descriptors performed substantially better than ligand-only ones, in terms of both $\mathrm{R}^{2}(0.64 \mathrm{v} 0.35)$ and root mean squared error $(0.66 \mathrm{v} 1.05 \mathrm{log}$ units $)$. They found that both the binding site amino acids and the protein sequence corresponded to important protein descriptors in their models.

\section{Relationship to Protein Structure Prediction}

Ain et al.'s finding that the best models require protein information (Ain et al., 2014) is particularly interesting. We recently asked why sequence-based protein function prediction methods work so effectively. For example, De Ferrari et al. obtained 98\% prediction accuracy for enzyme function, based on transferring annotations from a query sequence's nearest neighbor of known function (De Ferrari et al., 2012). We have recently demonstrated that the majority of the predictive power of such sequence signature-based methods comes from the wealth of evolutionary information contained in the whole sequence, and only a small part of the predictive ability emanates from the many fewer functionally essential conserved residues (Beattie et al., 2015). In the context of polypharmacology and off-target interactions, structure-based methods of protein function prediction (Laskowski et al., 2005; Pal and Eisenberg, 2005; Cuff et al., 2011) are also highly relevant. Unexpected ligand-target interactions can be discovered by cross-docking the library of compounds into the active sites of the known structures of the various proteins (Favia et al., 2008; Patel et al., 2015). This methodology, however, requires an experimental protein structure, or at least a high-quality structural model, for the target, and is computationally much more expensive than cheminformatics.

As well as predicting interactions with a protein's major functional site, which we term orthosteric, it is also possible to predict allosteric ligand function. For example, van Westen et al. predicted allosteric behavior of compounds based on structural and chemical descriptors and data from ChEMBL (van Westen et al., 2014). As well as such predictions of allosteric molecules, it is also important to be able to predict which proteins will be amendable to allosteric proteins and which residues or clefts may be involved. We have recently used a Random Forest model to predict the presence of allosteric binding sites on proteins, based on structure, solvent accessibility and predicted binding affinity (Chen et al., 2016). Other predictions of allostery are derived from reduced models of protein dynamics, for instance using normal mode analysis (Panjkovich and Daura, 2012) or modeling energy flow within the protein structure (Erman, 2011).

\section{VIRTUAL SCREENING OF MULTITARGET COMPOUNDS FOR CNS DISEASES}

Virtual Screening (VS) is widely used in drug discovery to reduce the enormous compound collections to a more manageable number for further synthesis and biological in vitro testing (Alvarez, 2004). The application of computational technologies has allowed medicinal chemists to develop new drugs in a time and cost-effective manner. Two generally accepted VS methods used in Computer Aided Drug Design (CADD) are classified as Ligand-Based Virtual Screening (LB-VS) and Structure-Based Virtual Screening (SB-VS) (Figure 5; Wilson 


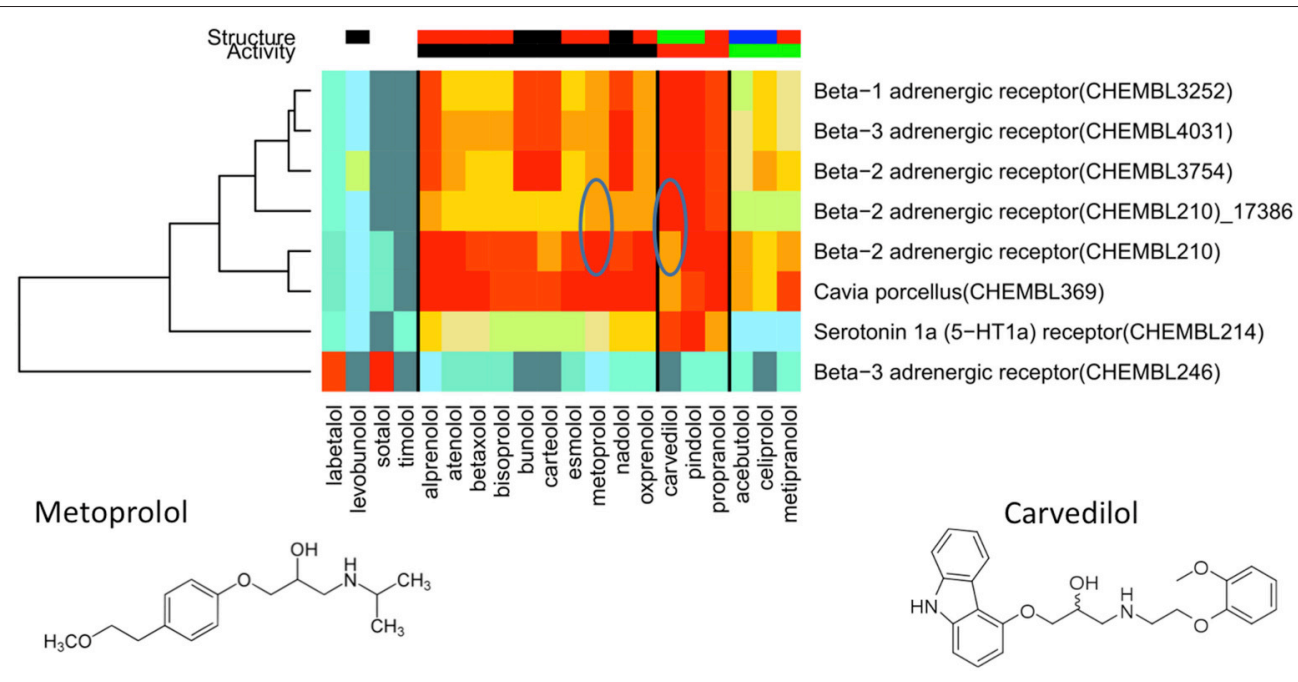

FIGURE 4 | Example case for the World Anti-Doping Agency data: the assignment of prohibited beta blockers to the Beta-2 adrenergic receptor family of ChEMBL (210).

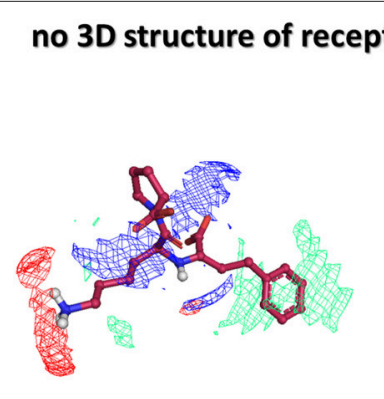

ligand based design

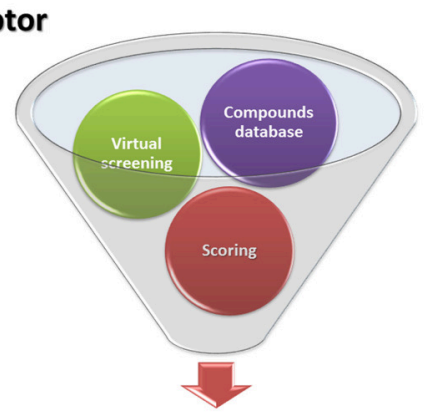

Hit list

\section{D structure of receptor}

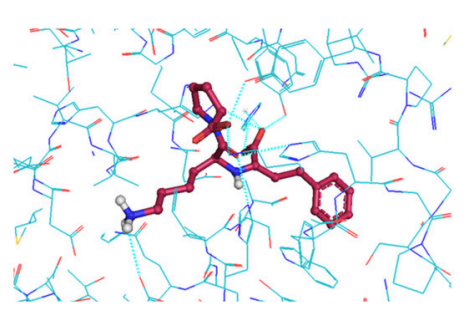

structure based design

FIGURE 5 | Schematic representation of the virtual screening strategy.

and Lill, 2011). Ligand-based VS approaches are often applied when no structural information about the target protein is available and analyze the physicochemical similarity between large compound databases and known active molecules. On the other hand, the structure-based VS approach applies different modeling techniques, often including docking, to mimic the binding interaction of ligands to a biomolecular target. In both VS approaches, structures from virtual libraries or commercial databases are compared to the template and scored. In recent years, besides the individual application of ligandand structure-based VS methods, combined techniques have also been proposed (Sperandio et al., 2008; Wilson and Lill, 2011). Even though docking is the most widely used approach in early phase drug discovery, a recent study has shown that ligand-based virtual screening methods in general yield a higher fraction of potent hits (Ripphausen et al., 2010). It is also important to note that hits with low nanomolar potency are rarely identified by VS (Eckert and Bajorath, 2007). However, compounds for further chemical exploration are predominantly provided.
Ligand-based VS applies two-dimensional (e.g., 2Dfingerprint) or three-dimensional (e.g., 3D-pharmacophore) searches between large compound databases and already known active molecules. This technique essentially neglects the target structure and allows a prioritization of molecules based on the Similar Property Principle, the assumption that compounds with similar descriptors tend to exhibit similar biological activity (Koeppen et al., 2011). Typically, topology-based descriptors of the known active compounds and the potential bioactive hits are compared to quantify molecular similarity. A major problem related to similarity methods is their bias toward input molecules and difficulty in making decision which structure to use as input (Venkatraman et al., 2010).

Beside similarity searching, the ligand-based pharmacophore method is also applied in VS. Pharmacophore models are usually built by using a set of structurally and functionally diverse ligands. This method is not only used to identify novel hit compounds, but also for profiling and anti-target modeling to avoid side-effects resulting from off-target activity (Schuster, 
2010). However, ligand-based virtual screening is often applied in combination with structure-based approaches to identify potential hit molecules.

In contrast to ligand-based approaches, which allow the identification of chemically similar ligands, SBVS offers the possibility of discovering ligands with new scaffolds or chemical functional groups. SBVS categories, such as shape similarity, structure-based pharmacophores and docking, require knowledge of the three-dimensional structure of target protein. Structures for target proteins are usually obtained by $\mathrm{X}$-ray crystallography or nuclear magnetic resonance (NMR) spectroscopy. In cases when this information does not exist, which is common in membrane receptors such as GPCRs, homology models can be used instead (Cavasotto, 2011). Structure-based pharmacophore models are developed on the basis of the active site and can be used to screen a compound database. Such pharmacophores are obtained by investigating all possible interaction sites in a binding pocket (Leach et al., 2010). Energy-based and geometry-based methods are applied to identify potentially important interaction sites and translate them into pharmacophore features. Typically, a binding pocket has a higher number of potential interaction sites than are normally observed actually being used in protein-ligand complexes.

The combination of the structure- and ligand-based VS strategies also occurs in many CADD studies (Drwal and Griffith, 2013). Sequential, parallel or hybrid combinations of VS techniques take into account all available chemical and biological information and thereby mitigate the drawbacks of each individual method (Figure 6; Hein et al., 2010; Wilson and Lill, 2011). Most of the recently published CADD studies apply a sequential VS approach (Khan et al., 2010; Weidlich et al., 2010; Drwal et al., 2011; Banoglu et al., 2012). In this approach ligand- and structure-based strategies are used in the VS protocol to gradually filter the large databases until the number of remaining potential hit compounds is small enough for biological testing. In parallel combination of VS methods, ligand- and structure-based strategies are run independently. Top ranked hit compounds are selected by a consensus aproach and processed for further biological testing. Benchmarking studies with retrospective analysis of performance have shown that successful application of parallel methods in VS is possible (Tan et al., 2008; Swann et al., 2011; Svensson et al., 2012). The Hybrid VS approach integrates ligand- and structure-based methods into one technique (protein-ligand pharmacophores) in order to enhance the accuracy of performance (Chen et al., 2010; Postigo et al., 2010; Spitzer et al., 2010; Drwal et al., 2011; Planesas et al., 2011).

During the last decade, many virtual screening methods have been developed and applied to discover novel potent ligands for the treatment of various neurological diseases. Several successful cases of reported virtual screening studies used to identify promising hits for CNS drugs discovery have been listed in Table 5. In this chapter we provide an overview of some of them that are significant from the polypharmacological point of view.

Lepailleur and co-workers applied pharmacophore-based virtual screening in combination with similarity based clustering method and molecular docking to identify dual
$\mathrm{H}_{3} \mathrm{R}$ antagonist/5 $\mathrm{HT}_{4} \mathrm{R}$ agonists (Lepailleur et al., 2014). Novel ligands would have potential for treatment of neurodegenerative diseases such as Alzheimer's disease. A three-dimensional pharmacophore model was constructed based on a set of six H3R antagonists developed by different pharmaceutical companies, using Catalyst software implemented in Discovery Studio 3.5 (Accelrys Inc., San Diego, CA, USA). This model was used as a search query for virtual screening of the CERMN chemical library (www.cermn.unicaen.fr) with a focus on serotonin (5-HT) "privileged structures". Binding experiments confirmed that benzo[h]-[1,6]naphthyridine ligands selected by this VS approach exert high affinity for both $\mathrm{H} 3$ and $5-\mathrm{HT}_{4}$ receptors. Recently, Bottegoni et al. carried out a virtual ligand screening protocol to identify fragments that display considerable activity at both $\beta$-secretase 1 (BACE-1) and glycogen synthase kinase $3 \beta$ (GSK-3 $\beta$ ) (Bottegoni et al., 2015). Discovery of multitarget drugs which are able to modulate BACE-1 and GSK-3 $\beta$ activity simultaneously represents a promising strategy in the treatment of Alzheimer's disease. In this study, a VS approach based on docking simulations and Tanimoto similarity analysis was applied on the ZINC database (www.zinc.docking.org). Top ranked compounds selected by VS were tested in vitro and one with activitiy in the low-micromolar range at both enzimes was identified as a hit. Potential acetylcholinesterase inhibitors were also discovered using a virtual screening approach, in combination with molecular docking (Lu et al., 2011). Threedimensional pharmacophore models were constructed based on a set of known AChE inhibitors. Virtual screening performed on the National Cancer Institute (NCI) compound database obtained nine new inhibitors that can block both catalytic and peripheral anionic sites of AChE. Designing or identifying dual-acting inhibitors that block both AChE binding sites is essential in preventing the degradation of acetylcholine in the brain and in protection of neurons from Abeta $(A \beta)$ toxicity.

Finally it can be concluded that most of the recent successfully performed drug discovery studies used a sequential combination of ligand and structure-based virtual screening techniques, with particular focus on pharmacophore models and the docking approach.

\section{Docking of Multi-Target Compounds for Neurodegenerative Diseases}

Docking is a computational technique that predicts the preferred orientation of one molecule toward the other (Lengauer and Rarey, 1996). It is widely utilized as a hit identification and lead optimization tool, before compound synthesis, if the structure of the target is reliably known (Kitchen et al., 2004). In this chapter, the focus will be on some of the most commonly used docking software (Table 6).

Ligand-protein docking samples the conformations of small molecules-igands-in binding sites of proteins, and scoring functions are used to evaluate which of these conformations best fits the protein binding site (Warren et al., 2006). Thus, it calculates and ranks the complexes resulting from the association between a certain ligand and a target protein of known three-dimensional structure (Sousa et al., 2006). Initially 


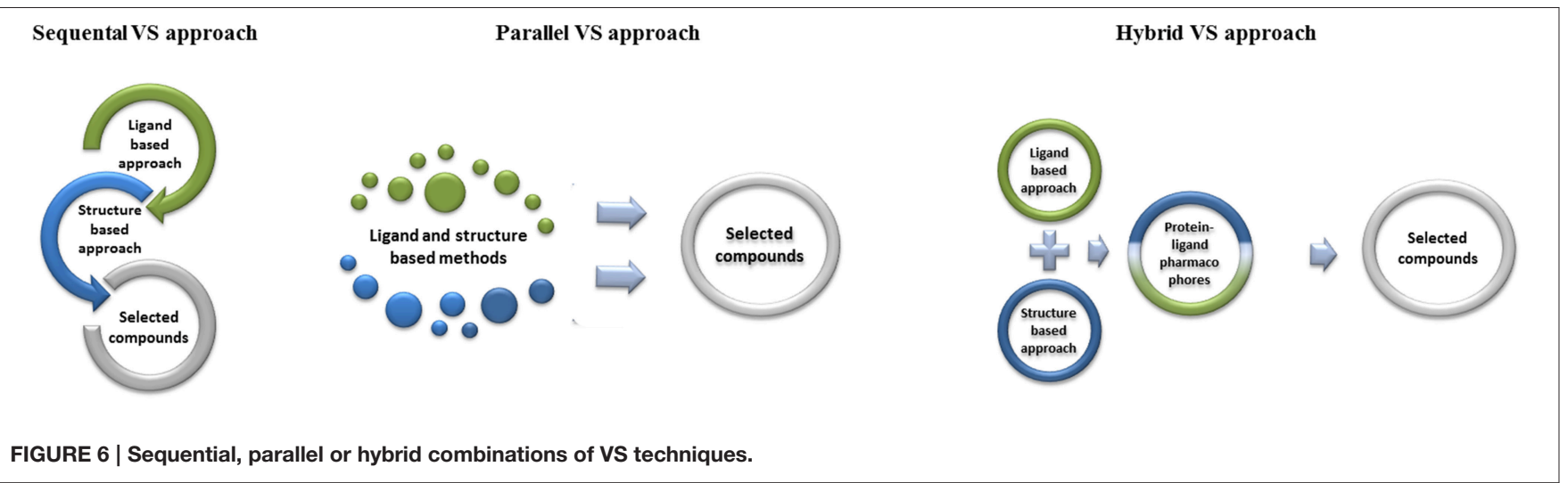

TABLE 5 | Reported virtual screening studies used in CNS drug discovery.

\begin{tabular}{|c|c|c|c|c|}
\hline Compounds & CNS diseases & Virtual screening method & Software package & References \\
\hline $\begin{array}{l}\text { BACE1 (beta-secretase 1) } \\
\text { inhibitors }\end{array}$ & $A D$ & $\begin{array}{l}\text { SB approach based on pharmacophore model } \\
\text { and molecular docking }\end{array}$ & $\begin{array}{l}\text { LigandScout } 1.03 \\
\text { www.inteligand.com GOLD } \\
3.2 \text { www.ccdc.cam.ac.uk }\end{array}$ & Vijayan et al., 2009 \\
\hline NK3 receptor antagonists & $\begin{array}{l}\text { Schizophrenia; } \\
\text { depression; anxiety }\end{array}$ & $\begin{array}{l}\text { Sequential similarity analysis followed by } \\
\text { CoMFA }\end{array}$ & $\begin{array}{l}\text { ROCS 2.4.1. and } 3.0 \\
\text { www.eyesopen.com }\end{array}$ & Geldenhuys et al., 2010 \\
\hline AChE inhibitors & $A D$ & $\begin{array}{l}\text { LB approach based on pharmacophore model } \\
\text { and molecular docking }\end{array}$ & $\begin{array}{l}\text { Discovery Studio } 2.5 .5 \\
\text { www.accelrys.com LibDock } \\
\text { (Diller and Merz, 2001) }\end{array}$ & Lu et al., 2011 \\
\hline $\begin{array}{l}\text { Human DOPA } \\
\text { Decarboxylase Inhibitors }\end{array}$ & PD & $\begin{array}{l}\text { SB approach based on pharmacophore model } \\
\text { and molecular docking }\end{array}$ & $\begin{array}{l}\text { MOE; Dovis 2.0; (Jiang } \\
\text { et al., 2008) AutoDock Vina } \\
\text { http://vina.scripps.edu/ }\end{array}$ & Daidone et al., 2012 \\
\hline $\begin{array}{l}\text { Histamine } \mathrm{H}_{3} \text { receptor } \\
\text { ligands }\end{array}$ & $\begin{array}{l}\text { PD; AD; epilepsy; } \\
\text { sleeping disorders }\end{array}$ & $\begin{array}{l}\text { LB and structure-based virtual fragment } \\
\text { screening }\end{array}$ & $\begin{array}{l}\text { FLAP } \\
\text { www.moldiscovery.com }\end{array}$ & Sirci et al., 2012 \\
\hline MAO-B inhibitors & PD & $\begin{array}{l}\text { LB virtual screening based on scaffold hopping } \\
\text { approach }\end{array}$ & $\begin{array}{l}\text { vROCS } 3.0 \\
\text { www.eyesopen.com }\end{array}$ & Geldenhuys et al., 2012 \\
\hline $\begin{array}{l}\text { SERT (serotonin transporter) } \\
\text { Inhibitors }\end{array}$ & Depression & $\begin{array}{l}\text { LB virtual screening based on two- and } \\
\text { three-dimensional similarities; flexibile docking }\end{array}$ & $\begin{array}{l}\text { JChem } \\
\text { www.chemaxon.com } \\
\text { Discovery studio }\end{array}$ & Gabrielsen et al., 2014 \\
\hline BuChE inhibitors & $A D$ & $\begin{array}{l}\text { LB virtual screening based on two- and } \\
\text { three-dimensional similarities }\end{array}$ & LiSiCA & Lešnik et al., 2015 \\
\hline $\begin{array}{l}\text { Serotonine } 5-\mathrm{HT}_{6} \\
\text { antagonists }\end{array}$ & $\begin{array}{l}\text { AD; schizophrenia; } \\
\text { obesity }\end{array}$ & $\begin{array}{l}\text { LB virtual approach based on two-dimensional } \\
\text { similarities and pharmacophore model }\end{array}$ & $\begin{array}{l}\text { InstJChem; } \\
\text { JChemForExcel; } \\
\text { www.chemaxon.com } \\
\text { Phase-program } \\
\text { www.schrodinger.com }\end{array}$ & Dobi et al., 2015 \\
\hline $\begin{array}{l}\mathrm{H}_{3} \mathrm{R} \text { antagonist } / 5 \mathrm{HT}_{4} \mathrm{R} \\
\text { agonist }\end{array}$ & $A D$ & $\begin{array}{l}\text { LB approach based on pharmacophore model } \\
\text { similarity based clustering method and } \\
\text { molecular docking }\end{array}$ & $\begin{array}{l}\text { Discovery Studio } 3.5 \\
\text { www.accelrys.com LibMCS } \\
\text { http://www.chemaxon.com/ } \\
\text { jchem/doc/user/LibMCS. } \\
\text { html Glide Induced-Fit } \\
\text { Docking http://www. } \\
\text { schrodinger.com/Induced- } \\
\text { Fit/ }\end{array}$ & Lepailleur et al., 2014 \\
\hline BACE-1/GSK-3 $\beta$ activity & $A D$ & $\begin{array}{l}\text { SB approach based on molecular docking } \\
\text { followed by Tanimoto ligand similarity }\end{array}$ & $\begin{array}{l}\text { Monte Carlo stochastic } \\
\text { optimizer implemented in } \\
\text { ICM (Abagyan and Totrov, } \\
\text { 1994) }\end{array}$ & Bottegoni et al., 2015 \\
\hline
\end{tabular}

rigid docking was used, where both target and compound were rigid. However, advances in both software and computer power mean that full flexibility on the ligand can now be allowed, and this approach is the most popular now. There are three general kinds of algorithms formulated to apply ligand flexibility: systematic methods, random or stochastic methods, and simulation methods. Systematic search algorithms explore all the degrees of freedom in a molecule, random search 
TABLE 6 | Recent docking studies employed to identify potential inhibitors for neurological targets.

\begin{tabular}{|c|c|c|c|}
\hline Compounds & CNS diseases & Software package & References \\
\hline MAO-A inhibitors & Depression & AutoDock http://autodock.scripps.edu/ & Evranos-Aksoz et al., 2015 \\
\hline Metallothionein-III inhibitors & $A D$ & Discovery Studio 2.5.5 www.accelrys.com & Roy et al., 2015 \\
\hline Sirtuin inhibitors & $A D$ & GLIDE http://www.schrodinger.com/Glide & Karaman and Sippl, 2015 \\
\hline $\begin{array}{l}\text { MAO-A, MAO-B, AChE, BuChE } \\
\text { inhibitors }\end{array}$ & $A D$ & GLIDE http://www.schrodinger.com/Glide & $\begin{array}{l}\text { Bautista-Aguilera et al., } \\
\text { 2014b,c }\end{array}$ \\
\hline AMPK2 inhibitors & Stroke & $\begin{array}{l}\text { AutoDock, FlexX } \\
\text { http://autodock.scripps.edu/ } \\
\text { https://www.biosolveit.de/FlexX/ }\end{array}$ & Park et al., 2014 \\
\hline MAO- B inhibitors & $P D, A D$ & AutoDock, GOLD, LibDock & Yelekci et al., 2013 \\
\hline Dopamine transporter inhibitors & ADHD, PD, depression and addiction & MOE https://www.chemcomp.com/ & Schmitt et al., 2010 \\
\hline
\end{tabular}

algorithms explore the conformational space by applying random changes to a single ligand or a group of ligands, and simulation methods utilize a different approach to the docking process such as molecular dynamics (MD) or energy minimization methods (Sousa et al., 2006). Also, many scoring functions have been reported over the years, and classified as forcefield-based, empirical, and knowledge-based. The first category uses available force fields to calculate the direct interactions between protein and ligand atoms (frequently comprising the non-covalent energy terms covering the electrostatic energy, the van der Waals (vdW), and hydrogen bonding). Secondly, an empirical scoring function calculates the fitness of proteinligand binding by summing up the contributions of various individual terms, each representing a significant energetic factor in protein-ligand binding. The third type of method utilizes pairwise statistical potentials between protein and ligand, based on the occurrence frequencies of particular atomatom interaction frequencies in databases of protein-ligand complex structures (Mitchell et al., 1999). Recently, methods that bring pharmacophore and structure-activity relationship (SAR) analysis into protein-ligand interaction assessment have been introduced, representing new trends in this field ( $\mathrm{Hu}$ and Lill, 2014).

Today, there are numerous docking software packages available, based on different search algorithms and scoring functions. None of the existing docking programs and scoring functions is uniquely excellent and the improvements are still continuing. The best way is to apply several docking programs in order to reduce the artifacts. The three widely used software tools are CDOCKER (Wu et al., 2003), GOLD (Jones et al., 1995) and AutoDock (Morris et al., 1998, 2009).

The usage of docking tools in discovery of novel compounds for neurodegenerative diseases could be explained through the example of our study on MAO -A and B inhibitors. The crystal structure of human MAO-A (hMAO-A) complexed with the reversible inhibitor harmine (PDB 2Z5X) (Son et al., 2008) and the crystal structure of human MAO-B (hMAO-B) co-crystallized with the reversible inhibitor safinamide (PDB 2V5Z) (Binda et al., 2007) were extracted from the Protein Data Bank (PDB) (Berman et al., 2000; http://www.rcsb.org) for protein setup. Studies were carried out on only one subunit of the enzymes. Each structure was cleaned of all water molecules and inhibitors and all non-interacting ions were removed before being used in the docking studies. For each protein, all hydrogens were added and the protein is minimized using the Discovery Studio protocol (accelrys.com), assigning a CHARMM force field. Missing hydrogen atoms were added on the basis of the protonation state of the titratable residues at a $\mathrm{pH}$ of 7.4. Ionic strength was set to 0.145 and the dielectric constant was set to 10. Molecular models of the inhibitors were built and optimized using SPARTAN 10.0. Docking was performed using AutoDock 4.2. For coordinates of the binding pocket, the N5 atom of the FAD molecule was taken, and the chosen region covers the entire binding site and its neighboring residues. Compounds were docked in both MAO$A$ and MAO-B and the selectivity was compared. To study the binding pose of these compounds, several representative ligands were chosen, the important interactions were visualized in the Accelrys Visualization 4.5. program. Analysis of binding modes revealed that aromatic groups of these compounds in hydrophobic cage of MAO-A and MAO-B enzymes were important for affinity (Figures 7, 8; Evranos-Aksoz et al., 2015).

\section{CONCLUDING REMARKS}

Extensive use of computational methods such as data mining, cheminformatics, QSAR modeling, virtual screening and docking, provide a time and cost efficient drug discovery processes.

These methods have become an integral part of drug discovery. A wide range of computational tools is being developed and used to obtain hits that are more likely to give potential clinical candidates. However, despite their success, both ligand- and structure-based techniques face challenges and limitations that should be considered during application. In recent years, integration of various cheminformatic, QSAR, virtual screening and docking protocols has become very popular, since it enhances their strength and applicability. This chapter focuses on various computation methodologies successfully applied in CNS drug discovery processes, such as 

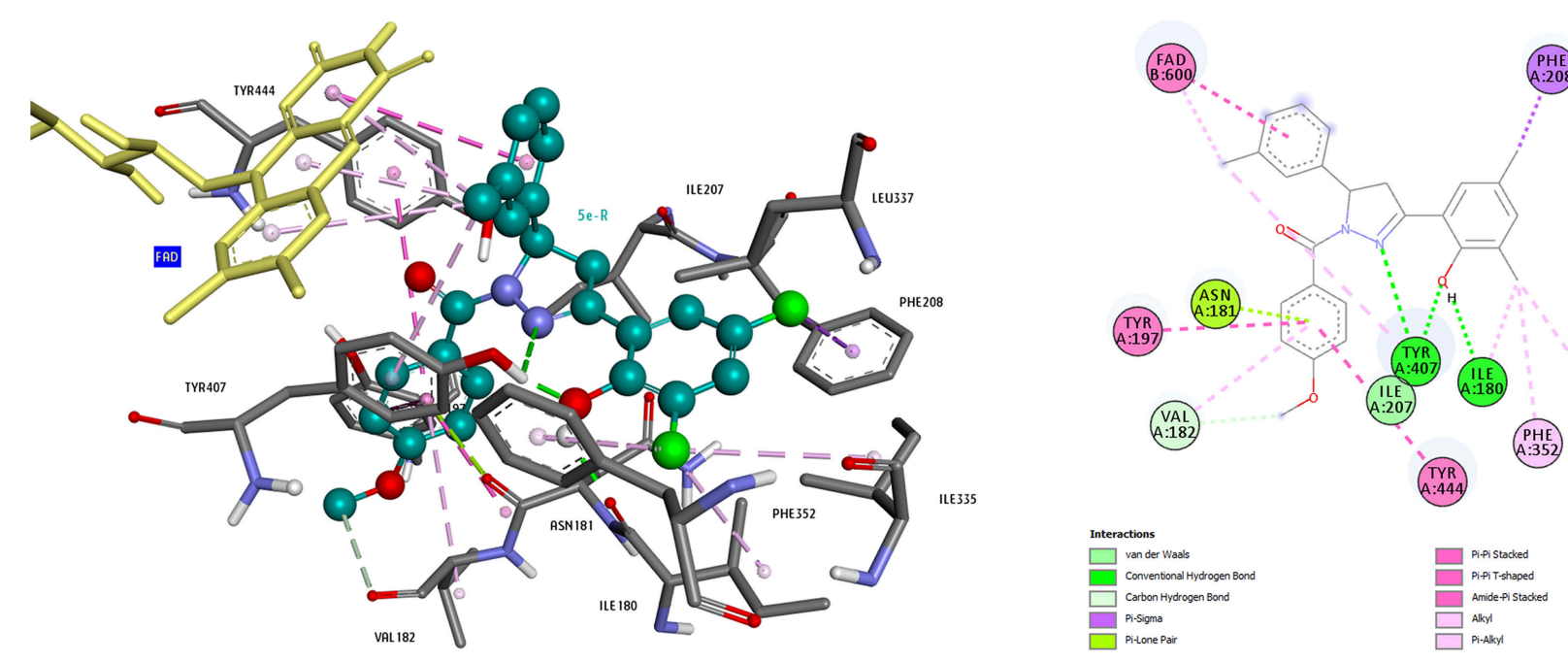

FIGURE 7 | 3D and 2D representations of compound $5 e(R)$ binding mode in the active site of MAO-A.

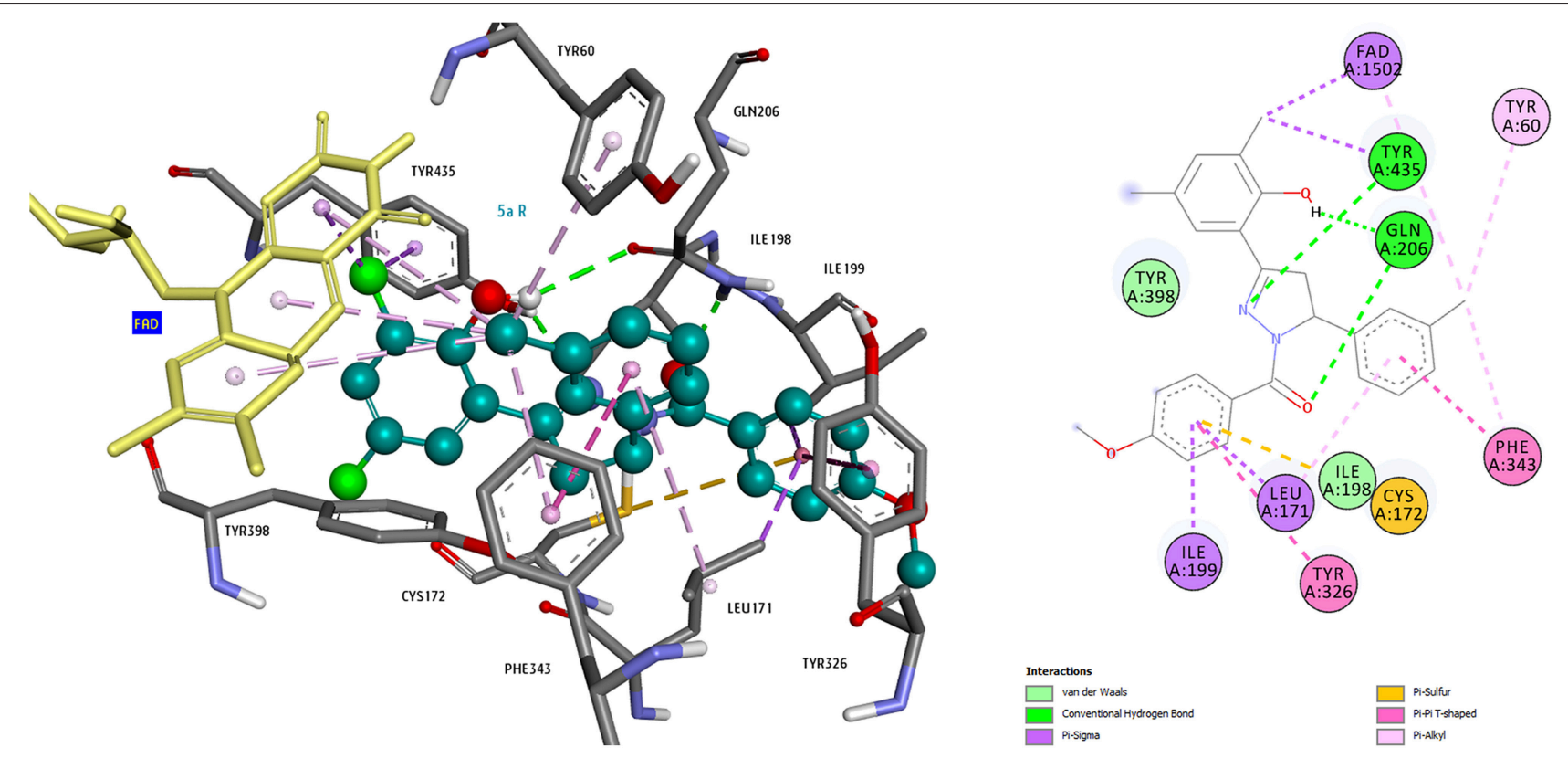

FIGURE 8 | 3D and 2D representations of compound $5 e(R)$ binding mode in the active site of MAO-B.

design of novel donepezil-indolyl hybrids, N-Methyl-N-((1methyl-5-(3-(1-(2-methylbenzyl)piperidin-4-yl)propoxy)-1Hindol-2-yl)methyl)prop-2-yn-1-amine, and donepezil-pyridyl hybrids, as multitarget inhibitors of acetylcholine esterase and MAO (AChE/BuChE/MAO-A/MAO-B) that were effective drug candidates for therapy of neurodegenerative Alzheimer's (AD) and Parkinson's diseases (PD).

Detailed analysis of the recently reported case studies revealed that the majority of them use a sequential combination of ligand and structure-based virtual screening techniques, with particular focus on pharmacophore models and the docking approach.

\section{AUTHOR CONTRIBUTIONS}

All authors contributed to the conception and interpretation of the work and to its critical revision. All authors have approved the final version and may be held accountable for the integrity of this review of current literature.

\section{ACKNOWLEDGMENTS}

Support was kindly provided by the EU COST Action CM1103. DA, KN, and JV kindly acknowledge national 
project number 172033 and OI1612039 supported by the Ministry of the Republic of Serbia. TD and KY kindly acknowledge "Training in Neurodegeneration, Therapeutics,
Intervention and Neurorepair" project number 608381 funded by Marie Skłodowska-Curie action, funding scheme: FP7-MC-ITN.

\section{REFERENCES}

Abagyan, R., and Totrov, M. (1994). Biased probability Monte Carlo conformational searches and electrostatic calculations for peptides and proteins. J. Mol. Biol. 235, 983-1002. doi: 10.1006/jmbi.1994.1052

Acharya, C., Coop, A., Polli, J. E., and Mackerell, A. D. Jr. (2011). Recent advances in ligand based drug design: relevance and utility of the conformationally sampled pharmacophore approach. Curr. Comput. Aided Drug Des. 7, 10-22. doi: 10.2174/157340911793743547

Ain, Q. U., Mendez-Lucio, O., Ciriano, I. C., Malliavin, T., van Westen, G. J. P., and Bender, A. (2014). Modelling ligand selectivity of serine proteases using integrative proteochemometric approaches improves model performance and allows the multi-target dependent interpretation of features. Integr. Biol. 6, 1023-1033. doi: 10.1039/c4ib00175c

Alelyunas, Y. W., Empfield, J. R., McCarthy, D., Spreen, R. C., Bui, K., PelosiKilby, L., et al. (2010). Experimental solubility profiling of marketed CNS drugs, exploring solubility limit of CNS discovery candidate. Bioorg. Med. Chem. Lett. 20, 7312-7316. doi: 10.1016/j.bmcl.2010.10.068

Alvarez, J. C. (2004). High-throughput docking as a source of novel drug leads. Curr. Opin. Chem. Biol. 8, 365-370. doi:10.1016/j.cbpa.2004.05.001

Amato, D. (2015). Serotonin in antipsychotic drugs action. Behav. Brain Res. 277C, 125-135. doi: 10.1016/j.bbr.2014.07.025

Anighoro, A., Bajorath, J., and Rastelli, G. (2014). Polypharmacology: challenges and opportunities in drug discovery. J. Med. Chem. 57, 7874-7887. doi: 10.1021/jm5006463

Apelt, J., Grassmann, S., Ligneau, X., Pertz, H. H., Ganellin, C. R., Arrang, J. M., et al. (2005). Search for histamine H3 receptor antagonists with combined inhibitory potency at Ntau-methyltransferase: ether derivatives. Pharmazie 60, 97-106.

Apelt, J., Ligneau, X., Pertz, H. H., Arrang, J. M., Ganellin, C. R., Schwartz, J. C., et al. (2002). Development of a new class of nonimidazole histamine $\mathrm{H}(3)$ receptor ligands with combined inhibitory histamine $\mathrm{N}$-methyltransferase activity. J. Med. Chem. 45, 1128-1141. doi: 10.1021/jm0110845

Bajda, M., Guzior, N., Ignasik, M., and Malawska, B. (2011). Multi-target-directed ligands in Alzheimer's disease treatment. Curr. Med. Chem. 18, 4949-4975. doi: 10.2174/092986711797535245

Banoglu, E., ÇaliÅ\$kan, B., Luderer, S., Eren, G., Özkan, Y., Altenhofen, W., et al. (2012). Identification of novel benzimidazole derivatives as inhibitors of leukotriene biosynthesis by virtual screening targeting 5lipoxygenase-activating protein (FLAP). Bioorg. Med. Chem. 20, 3728-3374. doi: 10.1016/j.bmc.2012.04.048

Bautista-Aguilera, O. M., Esteban, G., Bolea, I., Nikolic, K., Agbaba, D., Moraleda, I., et al. (2014a). Design, synthesis, pharmacological evaluation, QSAR analysis, molecular modeling and ADMET of novel donepezil-indolyl hybrids as multipotent cholinesterase/monoamine oxidase inhibitors for the potential treatment of Alzheimer's disease. Eur. J. Med. Chem. 75, 82-95. doi: 10.1016/j.ejmech.2013.12.028

Bautista-Aguilera, O. M., Esteban, G., Chioua, M., Nikolic, K., Agbaba, D., Moraleda, I., et al. (2014c). Multipotent cholinesterase/monoamine oxidase inhibitors for the treatment of Alzheimer's disease: design, synthesis, biochemical evaluation, ADMET, molecular modeling, and QSAR analysis of novel donepezil-pyridyl hybrids. Drug Des. Dev. Ther. 8, 1893-1910. doi: 10.2147/DDDT.S69258

Bautista-Aguilera, O. M., Samadi, A., Chioua, M., Nikolic, K., Filipic, S., Agbaba, D., et al. (2014b). N-Methyl-N-((1-methyl-5-(3-(1-(2-methylbenzyl)piperidin4-yl)propoxy)-1H-indol-2-yl)methyl)prop-2-yn-1-amine, a new cholinesterase and monoamine oxidase dual inhibitor J. Med. Chem. 57, 10455-10463. doi: 10.1021/jm501501a

Beattie, K. E., De Ferrari, L., and Mitchell, J. B. O. (2015). Why do sequence signatures predict enzyme mechanism? Homology versus chemistry. Evol. Bioinform. 11, 267-274. doi: 10.4137/ebo.s31482
Bender, A., Mussa, H. Y., Glen, R. C., and Reiling, S. (2004). Molecular similarity searching using atom environments, information-based feature selection and a naive bayesian classifier. J. Chem. Inf. Comput. Sci. 44, 170-178. doi: $10.1021 / \mathrm{ci034207y}$

Bender, A., Scheiber, J., Glick, M., Davies, J. W., Azzaoui, K., Hamon, J., et al. (2007). Analysis of pharmacology data and the prediction of adverse drug reactions and off-target effects from chemical structure. ChemMedChem. 2, 861-873. doi: $10.1002 / \mathrm{cmdc} .200700026$

Berman, H. M., Westbrook, J., Feng, Z., Gilliland, G., Bhat, T. N., Weissig, H., et al. (2000). The protein data bank. Nucleic Acids Res. 28, 235-242. doi: 10.1093/nar/28.1.235

Besnard, J., Ruda, G. F., Setola, V., Abecassis, K., Rodriguiz, R. M., Huang, X. P., et al. (2012). Automated design of ligands to polypharmacological profiles. Nature 492, 215-220. doi: 10.1038/nature11691

Binda, C., Wang, J., Pisani, L., Caccia, C., Carotti, A., Salvati, P., et al. (2007). Structures of human monoamine oxidase B complexes with selective noncovalent inhibitors: safinamide and coumarin analogs. J. Med. Chem. 50, 5848-5852. doi: 10.1021/jm070677y

Bolea, I., Gella, A., Monjas, L., Pérez, C., Rodríguez-Franco, M. I., MarcoContelles, J., et al. (2013). Multipotent, permeable drug ASS234 inhibits A $\beta$ aggregation, possesses antioxidant properties and protects from Abeta-induced apoptosis in vitro. Curr. Alzh. Res. 10, 797-808. doi: 10.2174/15672050113109 990151

Bolea, I., Juarez-Jimenez, J., de los Rios, C., Chioua, M., Pouplana, R., Luque, F. J., et al. (2011). Synthesis, biological evaluation, and molecular modeling of donepezil and $\mathrm{N}$-[(5-(Benzyloxy)-1-methyl-1H-indol-2yl)methyl]-nmethylprop-2-yn-1-amine hybrids as new multipotent cholinesterase/monoamine oxidase inhibitors for the treatment of Alzheimer's disease. J. Med. Chem. 54, 8251-8270. doi: 10.1021/jm200853t

Boran, A. D. W., and Iyengar, R. (2010). Systems approaches to polypharmacology and drug discovery. Curr. Opin. Drug Disc. 13, 297-309.

Bottegoni, G., Veronesi, M., Bisignano, P., Kacker, P., Favia, A. D., and Cavalli, A. (2015). Development and application of a virtual screening protocol for the identification of multitarget fragments. ChemMedChem. doi: 10.1002/cmdc.201500521. [Epub ahead of print].

Bourne, J. A. (2001). SCH 23390: the first selective dopamine D1-like receptor antagonist. CNS Drug. Rev. 7, 399-414. doi: 10.1111/j.15273458.2001.tb00207.x

Breiman, L. (2001). Random forests. Mach. Learn. 45, 5-32. doi: 10.1023/a:1010933404324

Brunton, L., Chabner, B., and Knollman, B. (2011). Goodman and Gilman's the Pharmacological Basis of Therapeutics. The McGraw-Hill Companies, Inc.

Buckley, P. F. (2003). Aripirazole: efficacy and tolerability profile of a novel-acting atypical antipsychotic. Drug. Today 39, 145-151. doi: 10.1358/dot.2003.39.2.799421

Carlsson, M., and Carlsson, A. (1990). Interactions between glutamatergic and monoaminergic systems within the basal ganglia - implications for schizophrenia and Parkinson 's disease. Trends Neurosci. 13, 272-276.

Cavasotto, C. N. (2011). Homology models in docking and highthroughput docking. Curr. Top Med. Chem. 11, 1528-1534. doi: 10.2174/156802611795860951

Chen, A. S. Y., Westwood, N. J., Brear, P., Rogers, G. W., Mavridis, L., and Mitchell, J. B. O. (2016). A random forest model for predicting allosteric and functional sites on proteins. Mol. Inf. 35, 125-135. doi: 10.1002/minf.201500108

Chen, B., Wild, D., and Guha, R. (2009). PubChem as a source of polypharmacology. J. Chem. Inf. Model. 49, 2044-2055. doi: 10.1021/ci9001876

Chen, Z., Tian, G., Wang, Z., Jiang, H., Shen, J., and Zhu, W. (2010). Multiple pharmacophore models combined with molecular docking: a reliable way for efficiently identifying novel PDE4 inhibitors with high structural diversity. J. Chem. Inf. Model. 50, 615-625. doi: 10.1021/ci9 004173 
Cherkasov, A., Muratov, E. N., Fourches, D., Varnek, A., Baskin, I. I., Cronin, M., et al. (2014). QSAR modeling: where have you been? Where are you going to? J. Med. Chem. 57, 4977-5010. doi: 10.1021/jm4004285

Coburg, Y., Kottke, T., Weizel, L., Ligneau, X., and Stark, H. (2009). Potential utility of histamine $\mathrm{H} 3$ receptor antagonist pharmacophore in antipsychotics. Bioorg. Med. Chem. Lett. 19, 538-542. doi: 10.1016/j.bmcl.2008.09.012

Craig, P. N. (1971). Interdependence between physical parameters and selection of substituent groups for correlation studies. J. Med. Chem. 14, 680-684.

Cramer, R. D. (2012). The inevitable QSAR renaissance. J. Comp. Aided Mol. Des. 26, 35-38. doi: 10.1007/s10822-011-9495-0

Cramer, R. D., Patterson, D. E., and Bunce, J. D. (1988). Comparative molecular field analysis (CoMFA). 1. Effect of shape on binding of steroids to carrier proteins. J. Am. Chem. Soc. 110, 5959-5967. doi: 10.1021/ja002 $26 \mathrm{a} 005$

Cuff, A., Redfern, O., Dessailly, B., and Orengo, C. A. (2011). "Exploiting protein structures to predict protein functions," in Protein Function Prediction for Omics Era, ed D. Kihara (Dordrecht: Springer Netherlands), 107-123.

Dai, H., Fu, Q., Shen, Y., Hu, W., Zhang, Z., Timmerman, H., et al. (2007). The histamine $\mathrm{H} 3$ receptor antagonist clobenpropit enhances GABA release to protect against NMDA induced excitotoxicity through the cAMP/protein kinase A pathway in cultured cortical neurons. Eur. J. Pharmacol. 563, 117-123. doi:10.1016/j.ejphar.2007.01.069

Daidone, F., Montioli, R., Paiardini, A., Cellini, B., Macchiarulo, A., Giardina, G., et al. (2012). Identification by virtual screening and in vitro testing of human DOPA decarboxylase inhibitors. PLoS ONE 7:e31610. doi: 10.1371/journal.pone.0031610

Decker, M. (2007). Recent advances in the development of hybrid molecules/designed multiple compounds with antiamnesic properties. Mini-Rev. Med. Chem. 7, 221-229. doi: 10.2174/1389557077800 59817

De Ferrari, L., Aitken, S., van Hemert, J., and Goryanin, I. (2012). EnzML: multi-label prediction of enzyme classes using InterPro signatures. BMC Bioinformatics 13:61. doi: 10.1186/1471-2105-13-61

Desai, P. V., Sawada, G. A., Watson, I. A., and Raub, T. J. (2013). Integration of in silico and in vitro tools for scaffold optimization during drug discovery: predicting P-glycoprotein efflux. Mol. Pharmaceut. 10, 1249-1261. doi: $10.1021 / \mathrm{mp} 300555 \mathrm{n}$

Di Giovanni, G., Di Matteo, V., Pierucci, M., and Esposito, E. (2008). Serotonindopamine interaction: electrophysiological evidence. Prog. Brain Res. 172, 45-71. doi: 10.1016/S0079-6123(08)00903-5

Diller, D. J., and Merz, K. M. (2001). High throughput docking for library design and library prioritization. Proteins 43, 113-124. doi: 10.1002/10970134(20010501)43:2<113::AID-PROT1023>3.0.CO;2-T

Di Matteo, V., Di Giovanni, G., Pierucci, M., and Esposito, E. (2008). Serotonin control of central dopaminergic function: focus on in vivo microdialysis studies. Prog. Brain Res. 172, 7-44. doi: 10.1016/S0079-6123(08) 00902-3

Dixon, S. L., Smondyrev, A. M., and Rao, S. N. (2006). PHASE: a novel approach to pharmacophore modeling and 3D database searching. Chem. Biol. Drug Des. 67, 370-372. doi: 10.1111/j.1747-0285.2006.00384.x

Dobi, K., Flachner, B., Pukáncsik, M., Máthé, E., Bognár, M., Szaszkó, M., et al. (2015). Combination of pharmacophore matching, 2D similarity search, and in vitro biological assays in the selection of potential 5-HT6 antagonists from large commercial repositories. Chem. Biol. Drug Des. 86, 864-880. doi: 10.1111/cbdd. 12563

Don, C. G., and Riniker, S. (2014). Scents and sense: in silico perspectives on olfactory receptors. J. Comp. Chem. 35, 2279-2287. doi: 10.1002/jcc. 23757

Drwal, M. N., Agama, K., Wakelin, L. P., Pommier, Y., and Griffith, R. (2011). Exploring DNA topoisomerase I ligand space in search of novel anticancer agents. PLoS ONE 6:25150. doi: 10.1371/journal.pone.0025150

Drwal, M. N., and Griffith, R. (2013). Combination of ligand- and structure-based methods in virtual screening. Drug Discov. Today Technol. 10, e395-e401. doi: 10.1016/j.ddtec.2013.02.002

Durán, A., Zamora, I., and , Pastor, M. (2009). Suitability of GRINDbased principal properties for the description of molecular similarity and ligand-based virtual screening. J. Chem. Inf. Model. 49, 2129-2138. doi: $10.1021 / \mathrm{ci} 900228 \mathrm{x}$
Eckert, H., and Bajorath, J. (2007). Molecular similarity analysis in virtual screening: foundations, limitations and novel approaches. Drug Discov. Today 12, 225-233. doi:10.1016/j.drudis.2007.01.011

Erman, B. (2011). Relationships between ligand binding sites, protein architecture and correlated paths of energy and conformational fluctuations. Phys. Biol. 8:056003. doi: 10.1088/1478-3975/8/5/056003

Esbenshade, T. A., Browman, K. E., Bitner, R. S., Strakhova, M., Cowart, M. D., and Brioni, J. D. (2008). The histamine $\mathrm{H} 3$ receptor: an attractive target for the treatment of cognitive disorders. Brit. J. Pharmacol. 154, 1166-1181. doi: 10.1038/bjp.2008.147

Evranos-Aksoz, B., Baysal, Är̆., Yabanoğlu-Çiftçi, S., Djikic, T., Yelekçi, K., Uçar, G., et al. (2015). Synthesis and screening of human Monoamine Oxidase-A inhibitor effect of new 2-pyrazoline and hydrazine derivatives. Arch. Pharm. Chem. Life Sci. 348, 1-14. doi: 10.1002/ardp.201500212

Favia, A. D., Nobeli, I., Glaser, F., and Thornton, J. M. (2008). Molecular docking for substrate identification: the short-chain dehydrogenases/reductases. J. Mol. Biol. 375, 855-874. doi: 10.1016/j.jmb.2007.10.065

Gabrielsen, M., Kurczab, R., Siwek, A., Wolak, M., Ravna, A. W., Kristiansen, K., et al. (2014). Identification of novel serotonin transporter compounds by virtual screening. J. Chem. Inf. Model. 54, 933-943. doi: 10.1021/ci400742s

Garduno-Torres, B., Treviño, M., Gutiérrez, R., and Arias-Montaño, J. A. (2007). Presynaptic histamine H3 receptors regulate glutamate, but not GABA release in rat thalamus. Neuropharmacology 52, 527-535. doi:10.1016/j.neuropharm.2006.08.001

Gaulton, A., Bellis, L. J., Bento, P. A., Chambers, J., Davies, M., Hersey, A., et al. (2012). ChEMBL: a large-scale bioactivity database for drug discovery. Nucleic Acids Res. 40, D1100-D1107. doi: 10.1093/nar/gkr777

Geldenhuys, W. J., Funk, M. O., Van der Schyf, C. J., and Carroll, R. T. (2012). A scaffold hopping approach to identify novel monoamine oxidase B inhibitors. Bioorg. Med. Chem. Lett. 22, 1380-1383. doi: 10.1016/j.bmcl.2011.12.056

Geldenhuys, W. J., Kuzenko, S. R., and Simmons, M. A. (2010). Virtual screening to identify novel antagonists for the $\mathrm{G}$ protein-coupled $\mathrm{NK}_{3}$ receptor. J. Med. Chem. 53, 8080-8088. doi: 10.1021/jm1010012

Gemkow, M. J., Davenport, A. J., Harich, S., Ellenbroek, B. A., Cesura, A., and Hallett, D. (2009). The histamine H3 receptor as a therapeutic drug target for CNS disorders. Drug Discov. Today 14, 509-515. doi: 10.1016/j.drudis.2009.02.011

Ghose, A. K., Herbertz, T., Hudkins, R. L., Dorsey, B. D., and Mallamo, J. P. (2012). Knowledge-based, central nervous system (CNS) lead selection and lead optimization for CNS drug discovery. ACS Chem. Neurosci. 3, 50-68. doi: $10.1021 / \mathrm{cn} 200100 \mathrm{~h}$

Gleeson, M. P. (2008). Generation of a set of simple, interpretable ADMET rules of thumb. J. Med. Chem. 51, 817-834. doi: 10.1021/jm701122q

Goedert, M., and Spillantini, M. G. A. (2006). A century of Alzheimer's disease. Science 314, 777-781. doi: 10.1126/science.1132814

Gohlke, H., and Klebe, G. (2002). DrugScore meets CoMFA: adaptation of fields for molecular comparison (AFMoC) or how to tailor knowledge-based pair-potentials to a particular protein. J. Med. Chem. 45, 4153-4170. doi: 10.1021/jm020808p

González-Díaz, H., Prado-Prado, F., and Ubeira, F. M. (2012). Predicting antimicrobial drugs and targets with the MARCH-INSIDE approach. Curr. Top. Med Chem. 8, 1676-1690. doi: 10.2174/156802608786786543

Goodford, P. J. (1985). A computational procedure for determining energetically favorable binding sites on biologically important macromolecules. J. Med. Chem. 28, 849-857.

Grassmann, S., Apelt, J., Ligneau, X., Pertz, H. H., Arrang, J. M., Ganellin, C. R., et al. (2004). Search for histamine $\mathrm{H}(3)$ receptor ligands with combined inhibitory potency at histamine N-methyltransferase: omegapiperidinoalkanamine derivatives. Arch. Pharm. (Weinheim) 337, 533-545. doi: 10.1002/ardp.200400897

Grassmann, S., Apelt, J., Sippl, W., Ligneau, X., Pertz, H. H., Zhao, Y. H., et al. (2003). Imidazole derivatives as a novel class of hybrid compounds with inhibitory histamine $\mathrm{N}$-methyltransferase potencies and histamine $\mathrm{H} 3$ receptor affinities. Bioorgan. Med. Chem. 11, 2163-2174. doi:10.1016/S09680896(03)00120-2

Hajjo, R., Grulke, C. M., Golbraikh, A., Setola, V., Huang, X. P., Roth, B. L., et al. (2010). Development, validation, and use of quantitative structure-activity relationship models of 5-hydroxytryptamine (2B) receptor ligands to identify 
novel receptor binders and putative valvulopathic compounds among common drugs. J. Med. Chem. 53, 7573-7586. doi: 10.1021/jm100600y

Hajjo, R., Setola, V., Roth, B. L., and Tropsha, A. (2012). Chemocentric informatics approach to drug discovery: identification and experimental validation of selective estrogen receptor modulators as ligands of 5-hydroxytryptamine-6 receptors and as potential cognition enhancers. J. Med. Chem. 55, 5704-5719. doi: $10.1021 /$ jm2011657

Hamacher, A., Weigt, M., Wiese, M., Hoefgen, B., Lehmann, J., and Kassack, M. U. (2006). Dibenzazecine compounds with a novel dopamine/5-HT2A receptor profile and 3D-QSAR analysis. BMC Pharmacol. 15, 6-11. doi: 10.1186/14712210-6-11

Hansch, C., Maloney, P. P., Fujita, T., and Muir, R. M. (1962). Correlation of biological activity of phenoxyacetic acids with hammett substituent constants and partition coefficients. Nature 194, 178-180. doi:10.1038/194178b0

Hansch, C., Unger, S. H., and Forsythe, A. B. (1973). Strategy in drug design. Cluster analysis as an aid in the selection of substituents. J. Med. Chem. 16, 1217-1222.

Hein, M., Zilian, D., and Sotriffer, C. A. (2010). Docking compared to 3D pharmacophores: the scoring function challenge. Drug Discov. Today 7, e229e239. doi: 10.1016/j.ddtec.2010.12.003

Hitchcock, S. A. (2012). Structural modifications that alter the P-glycoprotein efflux properties of compounds. J. Med. Chem. 55, 4877-4895. doi: $10.1021 / \mathrm{jm} 201136 \mathrm{z}$

Hitchcock, S. A., and Pennington, L. D. (2006). Structure-brain exposure relationships. J. Med. Chem. 49, 7559-7583. doi: 10.1021/jm060642i

Hopkins, A. L. (2008). Network pharmacology: the next paradigm in drug discovery. Nat. Chem. Biol. 4, 682-690. doi: 10.1038/nchembio.118

Hu, B., and Lill, M. A. (2014). PharmDock: a pharmacophore -based docking program. J. Cheminform. 6:14. doi: 10.1186/1758-2946-6-14

Humbert-Claude, M., Morisset, S., Gbahou, F., and Arrang, J. M. (2007). Histamine $\mathrm{H} 3$ and dopamine D2 receptor-mediated [35S]GTP $\gamma[\mathrm{S}]$ binding in rat striatum: evidence for additive effects but lack of interactions. Biochem. Pharmacol. 73, 1172-1181. doi:10.1016/j.bcp.2007.01.006

Jiang, X., Kumar, K., Hu, X., Wallqvist, A., and Reifman, J. (2008). DOVIS 2.0: an efficient and easy to use parallel virtual screening tool based on AutoDock 4.0. Chem. Cent. J. 2, 18. doi: 10.1186/1752-153X-2-18

Johnson, D. S., Choi, C., Fay, L. K., Favor, D. A., Repine, J. T., White, A. D., et al. (2011). Discovery of PF-00217830: aryl piperazine napthyridinones as D2 agonists for schizophrenia and bipolar disorder. Bioorg. Med. Chem. Lett. 21, 2621-2625. doi: 10.1016/j.bmcl.2011.01.059

Jones, G., Willett, P., and Glen, R. C. (1995). Molecular recognition of receptor sites using a genetic algorithm with a description of desolvation. J. Mol. Biol. 245, 43-53.

Karaman, B., and Sippl, W. (2015). Docking and binding free energy calculations of sirtuin inhibitors. Eur. J. Med. Chem. 93, 584-598. doi: 10.1016/j.ejmech.2015.02.045

Khan, K. M., Wadood, A., Ali, M., Zia-Ullah, Ul-Haq, Z., Lodhi, M. A., et al. (2010). Identification of potent urease inhibitors via ligand- and structurebased virtual screening and in vitro assay. J. Mol. Graph. Model. 28, 792-798. doi: 10.1016/j.jmgm.2010.02.004

Kinnings, S. L., Liu, N., Tonge, P. J., Jackson, R. M., Xie, L., and Bourne, P. E. (2011). A machine learning-based method to improve docking scoring functions and its application to drug repurposing. J. Chem. Inf. Model. 51, 408-419. doi: 10.1021/ci100369f

Kiss, B., Horváth, A., Némethy, Z., Schmidt, E., Laszlovszky, I., Bugovics, G., et al. (2010). Cariprazine (RGH-188), a dopamine $\mathrm{D}(3)$ receptor-preferring, $\mathrm{D}(3) / \mathrm{D}(2)$ J. Pharmacol. Exp. Ther. 333, 328-340. doi: 10.1124/jpet.109.1 60432

Kitchen, D. B., Decornez, H., Furr, J. R., and Bajorath, J. (2004). Docking and scoring in virual screening for drug discovery: methods and applications. Nat. Rev. Drug Discov. 3, 935-949. doi:10.1038/nrd1549

Klebe, G., Abraham, U., and Mietzner, T. (1994). Molecular similarity indexes in a comparative-analysis (CoMSIA) of drug molecules to correlate and predict their biological-activity. J. Med. Chem. 37, 4130-4146.

Knox, C., Law, V., Jewison, T., Liu, P., Ly, S., Frolkis, A., et al. (2011). DrugBank 3.0: a comprehensive resource for 'omics' research on drugs. Nucleic Acids Res. 39, D1035-D1041. doi: 10.1093/nar/gkq1126
Koeppen, H., Kriegl, J., Lessel, U., Tautermann, C. S., and Wellenzohn, B. (2011). "Ligand-based virtual screening," in Virtual Screening, ed C. Sotriffer (Weinheim: Wiley-VCH Verlag GmbH \& Co. KGaA), 61-85.

Kupershmidt, L., Amit, T., Bar-Am, O., Youdim, M. B., and Weinreb, O. (2012). The Novel multi-target iron chelating-radical scavenging compound M30 possesses beneficial effects on major hallmarks of Alzheimer's disease. Antiox. Redox Sign. 17, 860-877. doi: 10.1089/ars.2011.4279

Lakshmi, V., Kannan, V. S., and Boopathy, R. (2013). Identification of potential bivalent inhibitors from natural compounds for acetylcholinesterase through in silico screening using multiple pharmacophores. J. Mol. Graph. Model. 40, 72-79. doi: 10.1016/j.jmgm.2012.12.008

Laskowski, R. A., Watson, J. D., and Thornton, J. M. (2005). ProFunc: a server for predicting protein function from 3D structure. Nucleic Acids Res. 33, W89-W93. doi: 0.1093/nar/gki414

Leach, A. R., Gillet, V. J., Lewis, R. A., and Taylor, R. (2010). Three-dimensional pharmacophore methods in drug discovery. J. Med. Chem. 53, 539-558. doi: $10.1021 / \mathrm{jm} 900817 \mathrm{u}$

Leeson, P. D., and Davis, A. M. (2004). Time-related differences in the physical property profiles of oral drugs. J. Med. Chem. 47, 6338-6348. doi: 10.1021/jm049717d

Leeson, P. D., and Springthorpe, B. (2007). The influence of drug-like concepts on decision-making in medicinal chemistry. Nat. Rev. Drug Discov. 6, 881-890. doi:10.1038/nrd2445

Lengauer, T., and Rarey, M. (1996). Computational methods for biomolecular docking. Curr. Opin. Struct. Biol. 6, 402-406.

León, R., Garcia, A. G., and Marco-Contelles, J. (2013). Recent advances in the multitarget-directed ligands approach for the treatment of Alzheimer's disease. Med. Res. Rev. 33, 139-189. doi: 10.1002/med.20248

Lepailleur, A., Freret, T., Lemaître, S., Boulouard, M., Dauphin, F., Hinschberger, A., et al. (2014). Dual histamine H3R/serotonin 5-HT4R ligands with antiamnesic properties: pharmacophore-based virtual screening and polypharmacology. J. Chem. Inf. Model. 54, 1773-1784. doi: 10.1021/ci500157n

Lešnik, S., Štular, T., Brus, B., Knez, D., Gobec, S., Janežič, D., et al. (2015). LiSiCA: a software for ligand-based virtual screening and its application for the discovery of butyrylcholinesterase inhibitors. J. Chem. Inf. Model. 55, 1521-1528. doi: 10.1021/acs.jcim.5b00136

Li, Y. P., Weng, X., Ning, F. X., Ou, J. B., Hou, J. Q., Luo, H. B., et al. (2013). 3D-QSAR studies of azaoxoisoaporphine, oxoaporphine, and oxoisoaporphine derivatives as anti-AChE and anti-AD agents by the CoMFA method. J. Mol. Graph. Model. 41, 61-67. doi: 10.1016/j.jmgm.2013.02.003

Ligneau, X., Lin, J., Vanni-Mercier, G., Jouvet, M., Muir, J. L., Ganellin, C. R., et al. (1998). Neurochemical and behavioural effects of ciproxifan, a potent histamine H3-receptor antagonist. J. Pharmacol. Exp. Ther. 287, 658-666.

Ligneau, X., Morisset, S., Tardivel-Lacombe, J., Gbahou, F., Ganellin, C. R., Stark, H., et al. (2000). Distinct pharmacology of rat and human histamine $\mathrm{H}(3)$ receptors: role of two amino acids in the third transmembrane domain. $\mathrm{Br}$. J. Pharmacol. 131, 1247-1250. doi: 10.1038/sj.bjp.0703712

Lipina, T. V., Palomo, V., Gil, C., Martinez, A., and Roder, J. C. (2013). Dual Inhibitor of PDE7 and GSK-3-VP1.15 Acts as Antipsychotic and Cognitive Enhancer in C57BL/6J Mice. Neuropharmacology 64, 205-214. doi: 10.1016/j.neuropharm.2012.06.032

Lipina, T. V., Wang, M., Liu, F., and Roder, J. C. (2012). Synergistic Interactions between PDE4B and GSK-3: DISC1 Mutant Mice. Neuropharmacology 62, 1252-1262. doi: 10.1016/j.neuropharm.2011.02.020

Lounkine, E., Keiser, M. J., Whitebread, S., Mikhailov, D., Hamon, J., Jenkins, J. L., et al. (2012). Large-scale prediction and testing of drug activity on side-effect targets. Nature 486, 361-367. doi: 10.1038/nature11159

Lu, J. J., Pan, W., Hu, Y. J., and Wang, Y. T. (2012). Multi-target drugs: the trend of drug research and development. PLOS ONE 7:e40262. doi: 10.1371/journal.pone.0040262

Lu, S. H., Wu, J. W., Liu, H. L., Zhao, J. H., Liu, K. T., Chuang, C. K., et al. (2011). The discovery of potential acetylcholinesterase inhibitors: a combination of pharmacophore modeling, virtual screening, and molecular docking studies. J. Biomed. Sci. 18:8. doi: 10.1186/1423-0127-18-8

Marco-Contelles, J., León, R., de Los Ríos, C., Guglietta, A., Terencio, J., López, M. G., et al. (2006). Novel multipotent tacrine-dihydropyridine hybrids with improved acetylcholinesterase inhibitory and neuroprotective activities as 
potential drugs for the treatment of Alzheimer's disease. J. Med. Chem. 49, 7607-7610. doi: 10.1021/jm061047j

Marco-Contelles, J., León, R., de los Ríos, C., Samadi, A., Bartolini, M., Andrisano, V., et al. (2009). Tacripyrines, the first tacrine-dihydropyridine hybrids, as multitarget-directed ligands for the treatment of Alzheimer's disease. J. Med. Chem. 52, 2724-2732. doi: 10.1021/jm801292b

Mavridis, L., and Mitchell, J. B. O. (2013). Predicting the protein targets for athletic performance-enhancing substances. J. Cheminformatics 5:31. doi: 10.1186/1758-2946-5-31

Mavridis, L., Nath, N., and Mitchell, J. B. O. (2013). PFClust: a novel parameter free clustering algorithm. BMC Bioinformatics 14:213. doi: 10.1186/1471-210514-213

Meltzer, H. Y., Massey, B. W., and Horiguchi, M. (2012). Serotonin receptors as targets for drugs useful to treat psychosis and cognitive impairment in schizophrenia. Curr. Pharm. Biotechnol. 13, 1572-1586. doi: $10.2174 / 138920112800784880$

Mestres, J., and Gregori-PuigjaneİĄ, E. (2009). Conciliating binding efficiency and polypharmacology. Trends Pharmacol. Sci. 30, 470-474. doi: 10.1016/j.tips.2009.07.004

Millan, M. J. (2005). N-Methyl-d-aspartate receptors as a target for improved antipsychotic agents: novel insights and clinical perspectives. Psychopharmacology 179, 30-53. doi: 10.1007/s00213-005-2199-1

Millan, M. J. (2006). Multi-target strategies for the improved treatment of depressive states: conceptual foundation and neuronal substrates, drug discovery and therapeutic application. Pharmacol. Therapeut. 110, 135-370. doi: 10.1016/j.pharmthera.2005.11.006

Millan, M. J. (2014). On 'polypharmacy' and multi-target agents, complementary strategies for improving the treatment of depression: a comparative appraisal. Int. J. Neuropsychopharmacol. 17, 1009-1037. doi: 10.1017/S1461145712001496

Mitchell, J. B. O., Laskowski, R. A., Alex, A., and Thornton, J. M. (1999). BLEEP - potential of mean force describing protein-ligand interactions: I. Generating potential. J. Comput. Chem. 20, 1165-1176.

Morphy, R., and Rankovic, Z. (2005). Designed multiple ligands. An emerging drug discovery paradigm. J. Med. Chem. 48, 6523-6543. doi: 10.1021/jm058225d

Morris, G. M., Goodsell, D. S., Halliday, R. S., Huey, R., Hart, W. E., Belew, R. K., et al. (1998). Automated docking using a Lamarckian genetic algorithm and empirical binding free energy function. J. Comput. Chem. 19, 1639-1662.

Morris, G. M., Huey, R., Lindstrom, W., Sanner, M. F., Belew, R. K., Goodsell, D. S., et al. (2009). Autodock4 and AutoDockTools4: automated docking with selective receptor flexiblity. J. Comput. Chem. 30, 2785-2791. doi: $10.1002 /$ jcc. 21256

Napolitano, F., Zhao, Y., Moreira, V., Tagliaferri, R., Kere, J., D’Amato, M., et al. (2013). Drug repositioning: a machine-learning approach through data integration. J. Cheminformatics 5:30. doi: 10.1186/1758-2946-5-30

Nikolic, K., Agbaba, D., and Stark, H. (2015a). Pharmacophore modeling, drug design and virtual screening on multi-targeting procognitive agents approaching histaminergic pathways. J. Taiwan Inst. Chem. E. 46, 15-29. doi:10.1016/j.jtice.2014.09.017

Nikolic, K., Mavridis, L., Bautista-Aguilera, O. M., Marco-Contelles, J., Stark, H., do Carmo Carreiras, M., et al. (2015b). Predicting targets of compounds against neurological diseases using cheminformatic methodology. J. Comput. Aided Mol. Des. 29, 183-198. doi: 10.1007/s10822-014-9816-1

Ning, X., Rangwala, H., and Karypis, G. (2009). Multi-Assay-based structureactivity relationship models: improving structure-activity relationship models by incorporating activity information from related targets. J. Chem. Inform. Mod. 49, 2444-2456. doi: 10.1021/ci900182q

Pajouhesh, H., and Lenz, G. R. (2005). Medicinal chemical properties of successful central nervous system drugs. NeuroRx 2, 541-553. doi: 10.1602 /neurorx.2.4.541

Pal, D., and Eisenberg, D. (2005). Inference of protein function from protein structure. Structure 13, 121-130. doi:10.1016/j.str.2004.10.015

Panjkovich, A., and Daura, X. (2012). Exploiting protein flexibility to predict the location of allosteric sites. BMC Bioinformatics 13:273. doi: 10.1186/1471-2105$13-273$

Pardridge, W. M. (2005). The blood-brain barrier: bottleneck in brain drug development. NeuroRx 2, 3-14. doi: 10.1602/neurorx.2.1.3
Park, H., Eom, J. W., and Kim, Y. H. (2014). Consensus scoring approach to identify the inhibitors of AMPA activated protein kinase $\alpha 2$ with virtual screening. J. Chem. Inf. Model. 54, 2139-2146. doi: 10.1021/ci500214e

Parzen, E. (1962). On estimation of a probability density function and mode. Ann. Math. Statist. 33, 1065-1076.

Pastor, M., Cruciani, G., McLay, I., Pickett, S., and Clementi, S. (2000). GRidINdependent descriptors (GRIND): a novel class of alignment- independent three-dimensional molecular descriptors. J. Med. Chem. 43, 3233-3243. doi: 10.1021/jm000941m

Patel, H., Lucas, X., Bendik, I., Günther, S., and Merfort, I. (2015). Target fishing by cross-docking to explain polypharmacological effects. ChemMedChem. 10, 1209-1217. doi: 10.1002/cmdc.201500123

Pérez, V., Marco, J. L., Fernández-Alvarez, E., and Unzeta, M. (1999). Relevance of benzyloxy group in 2-indolyl methylamines in the selective MAO-B inhibition. Brit. J. Pharmacol. 127, 869-876. doi: 10.1038/sj.bjp.0702600

Peters, J. U. (2013). Polypharmacology-foe or friend? J. Med. Chem. 56, 8955-8971. doi: 10.1021/jm400856t

Petroianu, G., Arafat, K., Sasse, B. C., and Stark, H. (2006). Multiple enzyme inhibitions by histamine $\mathrm{H} 3$ receptor antagonists as potential procognitive agents. Pharmazie 61, 179-182.

Planesas, J. M., Claramunt, R. M., Teixidó, J., Borrell, J. I., and Pérez-Nueno, V. I. (2011). Improving VEGFR-2 docking-based screening by pharmacophore postfiltering and similarity search postprocessing. J. Chem. Inf. Model. 51, 777-787. doi: 10.1021/ci1002763

Postigo, M. P., Guido, R. V., Oliva, G., Castilho, M. S., da R Pitta, I., de Albuquerque, J. F., et al. (2010). Discovery of new inhibitors of Schistosoma mansoni PNP by pharmacophore-based virtual screening. J. Chem. Inf. Model. 50, 1693-1705. doi: 10.1021/ci100128k

Prado-Prado, F., García-Mera, X., Escobar, M., Alonso, N., Caamaño, O., Yañez, M., et al. (2012). 3D MI-DRAGON: new model for the reconstruction of US FDA drug- target network and theoretical-experimental studies of inhibitors of rasagiline derivatives for AChE. Curr. Top. Med. Chem. 12, 1843-1865. doi: $10.2174 / 1568026611209061843$

Quesseveur, G., Nguyen, H. T., Gardier, A. M., and Guiard, B. P. (2012). 5-HT2 ligands in the treatment of anxiety and depression. Expert Opin. Inv. Drug. 21, 1701-1725. doi: 10.1517/13543784.2012.719872

Rajagopalan, R., Bandyopadhyaya, A., Rajagopalan, D. R., and Rajagopalan, P. (2014). The synthesis and comparative receptor binding affinities of novel, isomeric pyridoindolobenzazepine scaffolds. Bioorg. Med. Chem. Lett. 24, 576-579. doi: 10.1016/j.bmcl.2013.12.024

Rankovic, Z. (2015a). "Designing CNS drugs for optimal brain exposure" in BloodBrain Barrier in Drug Discovery: Optimizing Brain Exposure of CNS Drugs and Minimizing Brain Side Effects, 1st Edn., eds L. Di and E. H. Kerns (New York, NY: Wiley), 385-425.

Rankovic, Z. (2015b). CNS drug design: balancing physicochemical properties for optimal brain exposure. J. Med. Chem. 58, 2584-2608. doi: 10.1021/jm501535r

Rankovic, Z., and Bingham, M. (2013). "Medicinal chemistry challenges in CNS drug discovery," in Drug Discovery for Psychiatric Disorders, 1st Edn., eds Z. Rankovic, M. Bingham, E. Nestler, and R. Hargreaves (London: Royal Society of Chemistry), 465-509.

Raub, T. J., Lutzke, B. S., Andrus, P. K., Sawada, G. A., and Staton, B. A. (2006). "Early preclinical evaluation of brain exposure in support of hit identification and lead optimization," in Optimizing the 'Drug-Like' Properties of Leads in Drug Discovery, eds R. T. Borchardt, E. H. Kerns, M. J. Hageman, D. R. Thakker, and J. L. Stevens (New York, NY: Springer), 355-410.

Reinikainen, K. J., Soininen, H., and Riekkinen, P. J. (1990). Neurotransmitter changes in Alzheimer's disease: implications to diagnostics and therapy. $J$. Neurosci. Res. 27, 576-586.

Remington, G. (2003). Understanding antipsychotic "atypicality": a clinical and pharmacological moving target. J. Psychiatr. Neurosci. 28, 275-284.

Reynolds, G. P. (2004). Receptor mechanisms in the treatment of schizophrenia. J. Psychopharmacol. 18, 340-345. doi: 10.1177/0269881104044562

Ripphausen, P., Nisius, B., Peltason, L., and Bajorath, J. (2010). Quo vadis, virtual screening? A comprehensive survey of prospective applications. J. Med. Chem. 53, 8461-8467. doi: 10.1021/jm101020z

Rosenblatt, M. (1956). Remarks on some nonparametric estimates of a density function. Ann. Math. Statist. 27, 832-837. 
Roth, B. L., Sheffler, D. J., and Kroeze, W. K. (2004). Magic shotguns versus magic bullets: selectively non-selective drugs for mood disorders and schizophrenia. Nat. Rev. Drug Discov. 3, 353-359. doi: 10.1038/nr d1346

Roy, S., Kumar, A., Baig, M. H., MasaÅŹík, M., and Provazník, I. (2015). Virtual screening, ADMET profiling, molecular docking and dynamics approaches to search for potent selective natural molecules based inhibitors against metallothionein-III to study Alzheimer's disease. Methods 83, 105-110. doi: 10.1016/j.ymeth.2015.04.021

Sander, K., Kottke, T., and Stark, H. (2008). Histamine H3 receptor antagonists go to clinics. Biol. Pharm. Bull. 31, 2163-2181. doi: 10.1248/bpb.3 1.2163

Schmitt, K. C., Mamidyala, S., Biswas, S., Dutta, A. K., and Reith, M. E. (2010). Bivalent phenethylamines as novel dopamine transporter inhibitors: evidence for multiple substrate-binding sites in a single transporter. J. Neurochem. 112, 1605-1618. doi: 10.1111/j.1471-4159.2010.06583.x

Schuster, D. (2010). 3D pharmacophores as tools for activity profiling. Drug Discov. Today Technol. 7, e203-e270. doi: 10.1016/j.ddtec.2010. 11.006

Sedvall, G. C., and Karlsson, P. (2006). Pharmacological manipulation of D1dopamine receptor function in schizophrenia. Neuropsychopharmacol. 21, S181-S188. doi:10.1016/S0893-133X(99)00104-9

Shapiro, D. A., Renock, S., Arrington, E., Chiodo, L. A., Liu, L. X., Sibley, D. R., et al. (2003). Aripiprazole, a novel atypical antipsychotic drug with a unique and robust pharmacology. Neuropsychopharmacology 28, 1400-1411. doi:10.1038/sj.npp.1300203

Sirci, F., Istyastono, E. P., Vischer, H. F., Kooistra, A. J., Nijmeijer, S., Kuijer, M., et al. (2012). Virtual fragment screening: discovery of histamine H3 receptor ligands using ligand-based and protein-based molecular fingerprints. J. Chem. Inf. Model. 52, 3308-3324. doi: 10.1021/ci3004094

Son, S. Y., Ma, J., Kondou, Y., Yoshimura, M., Yamashita, E., and Tsukihara, T. (2008). Structure of human monoamine oxidase A at 2.2-A resolution: the control of opening the entry for substrates/inhibitors. Proc. Natl. Acad. Sci. U.S.A.105, 5739-5744. doi:10.1073/pnas.0710626105

Sousa, S. F., Fernandes, P. A., and Ramos, M. J. (2006). Protein-ligand docking: current status and future challenges. Proteins 65, 15-26. doi: $10.1002 /$ prot. 21082

Sperandio, O., Miteva, M. A., and Villoutreix, B. O. (2008). Combining ligandand structure-based methods in drug design projects. Curr. Comput-Aid Drug 4, 250-258. doi: 10.2174/157340908785747447

Spitzer, G. M., Heiss, M., Mangold, M., Markt, P., Kirchmair, J., Wolber, G., et al. (2010). One concept, three implementations of 3D pharmacophore-based virtual screening: distinct coverage of chemical search space. J. Chem. Inf. Model. 50, 1241-1247. doi: 10.1021/ci10 $0136 \mathrm{~b}$

Steinbeck, C., Han, Y., Kuhn, S., Horlacher, O., Luttmann, E., and Willighagen, E. (2003). The chemistry development kit (CDK): an open-source java library for chemo- and bioinformatics. J. Chem. Inf. Comput. Sci. 43, 493-500. doi: $10.1021 / \mathrm{ci0} 25584 \mathrm{y}$

Svensson, F., Karlén, A., and Sköld, C. (2012). Virtual screening data fusion using both structure- and ligand-based methods. J. Chem. Inf. Model. 52, 225-232. doi: 10.1021/ci2004835

Swann, S. L., Brown, S. P., Muchmore, S. W., Patel, H., Merta, P., and Locklear, J. (2011). A unified, probabilistic framework for structure- and ligandbased virtual screening. J. Med. Chem. 54, 1223-1232. doi: 10.1021/jm10 13677

Tan, L., Geppert, H., Sisay, M. T., Gütschow, M., and Bajorath, J. (2008). Integrating structure- and ligand-based virtual screening: comparison of individual, parallel, and fused molecular docking and similarity search calculations on multiple targets. Chem. Med. Chem. 3, 1566-1571. doi: $10.1002 / \mathrm{cmdc} .200800129$

Tauscher, J., Hussain, T., Agid, O., Verhoeff, N. P., Wilson, A. A., Houle, S., et al. (2004). Equivalent occupancy of dopamine D1 and D2 receptors with clozapine: differentiation from other atypical antipsychotics. Am. J. Psychiatr. 161, 1620-1625. doi: 10.1176/appi.ajp.161.9.1620
Threlfell, S., Cragg, S. J., Kalló, I., Turi, G. F., Coen, C. W., and Greenfield, S. A. (2004). Histamine H3 receptors inhibit serotonin release in substantia nigra pars reticulata. J. Neurosci. 24, 8704-8710. doi: 10.1523/JNEUROSCI.269004.2004

Topliss, J. G. (1972). Utilization of operational schemes for analog synthesis in drug design. J. Med. Chem. 15, 1006-1011.

van Westen, G. J. P., Gaulton, A., and Overington, J. P. (2014). Chemical, target, and bioactive properties of allosteric modulation. PLoS Comput. Biol. 10:e1003559. doi: 10.1371/journal.pcbi.1003559

Varela, R., Walters, W. P., Goldman, B. B., and Jain, A. N. (2012). Iterative refinement of a binding pocket model: active computational steering of lead optimization. J. Med. Chem. 55, 8926-8942. doi: 10.1021/jm30 $1210 \mathrm{j}$

Venkatraman, V., Pérez-Nueno, V. I., Mavridis, L., and Ritchie, D. W. (2010). Comprehensive comparison of ligand-based virtual screening tools against the DUD data set reveals limitations of current 3D methods. J. Chem. Inf. Model. 50, 2079-2093. doi: 10.1021/ci100263p.

Verloop, A., Hoogenstraaten, W., and Tipker, J. (1976). "Development and application of new steric substituent parameters in drug design," in Drug Design, ed E. J. Ariens (New York, NY: Academic Press), 165-207.

Vijayan, R. S., Prabu, M., Mascarenhas, N. M., and Ghoshal, N. (2009). Hybrid structure-based virtual screening protocol for the identification of novel BACE1 inhibitors. J. Chem. Inf. Model. 49, 647-657. doi: 10.1021/ci80 0386v

Warren, G. L., Andrews, C. W., Capelli, A. M., Clarke, B., LaLonde, J., Lambert, M. H., et al. (2006). A critical assessment of docking programs and scoring functions. J. Med. Chem. 49, 5912-5931. doi: 10.1021/jm05 $0362 \mathrm{n}$

Weidlich, I. E., Dexheimer, T., Marchand, C., Antony, S., Pommier, Y., and Nicklaus, M.C. (2010). Inhibitors of human tyrosyl-DNA phosphodiesterase (hTdp1) developed by virtual screening using ligand-based pharmacophores. Bioorg. Med. Chem. 18, 182-189. doi: 10.1016/j.bmc.2009. 11.008

Weiss, M. M., Williamson, T., Babu-Khan, S., Bartberger, M. D., Brown, J., Chen, K., et al. (2012). Design and preparation of a potent series of hydroxyethylamine containing $\beta$-secretase inhibitors that demonstrate robust reduction of central $\beta$-amyloid. J. Med. Chem. 55, 9009-9024. doi: 10.1021/jm30 $0119 \mathrm{p}$

Wilson, G. I., and Lill, M. A. (2011). Integrating structure-based and ligand-based approaches for computational drug design. Future Med. Chem. 3, 735-750. doi: $10.4155 /$ fmc. 11.18

Witkin, J. M., and Nelson, D. L. (2004). Selective histamine H3 receptor antagonists for treatment of cognitive deficiencies and other disorders of the central nervous system. Pharmacol. Therapeut. 103, 1-20. doi:10.1016/j.pharmthera.2004.05.001

Wold, S., Ruhe, A., Wold, H., and Dunn, W. J. (1984). The collinearity problem in linear regression. The partial least squares (PLS) approach to generalized inverses. SIAM J. Sci. Stat. Comput. 5, 735-743. doi: 10.1137/0905052

Wu, G. S., Robertson, D. H., Brooks, C. L. III., and Vieth, M. (2003). Detailed analysis of grid-based molecular docking: a case study of CDOCKER-A CHARMm-based MD docking algorithm. J. Comput. Chem. 24, 1549-1562. doi: $10.1002 /$ jcc.10306

Wu, W. L., Burnett, D. A., Spring, R., Greenlee, W. J., Smith, M., Favreau, L., et al. (2005). Dopamine D1/D5 receptor antagonists with improved pharmacokinetics: design, synthesis, and biological evaluation of phenol bioisosteric analogues of benzazepine D1/D5 antagonists. J. Med. Chem. 48, 680-693. doi: 10.1021/jm030614p

Ye, N., Song, Z., and Zhang, A. (2014). Dual ligands targeting dopamine D2 and serotonin 5-HT1A receptors as new antipsychotical on anti-parkinsonian agents. Curr. Med. Chem. 21, 437-457. doi: 10.2174/092986731132066 60300

Yelekci, K., Büyüktürk, B., and Kayrak, N. (2013). In silico identification of novel and selective monoamine oxidase B inhibitors. J. Neural. Transm. 120, 853-858. doi: 10.1007/s00702-012-0954-0 
Youdim, M. B., Edmondson, D., and Tipton, K. F. (2006). The therapeutic potential of monoamine oxidase inhibitors. Nat. Rev. Neurosci. 7, 295-309. doi:10.1038/nrn1883

Youdim, M. B. H., and Buccafusco, J. J. (2005). Multi-functional drugs for various CNS targets in the treatment of neurodegenerative disorders. Trends Pharmacol. Sci. 26, 27-35. doi:10.1016/j.tips.2004. 11.007

Zhang, L., Fourches, D., Sedykh, A., Zhu, H., Golbraikh, A., Ekins, S., et al. (2013). Discovery of novel antimalarial compounds enabled by QSARbased virtual screening. J. Chem. Inf. Model. 53, 475-492. doi: 10.1021/ci30 $0421 \mathrm{n}$

Zheng, H., Fridkin, M., and Youdim, M. B. (2010). Site-activated chelators derived from anti-parkinson drug rasagiline as a potential safer and more effective approach to the treatment of Alzheimer's disease. Neurochem. Res. 35, 2117-2123. doi: 10.1007/s11064-010-0293-1
Conflict of Interest Statement: The authors declare that the research was conducted in the absence of any commercial or financial relationships that could be construed as a potential conflict of interest.

The handling Editor declared a shared affiliation with one of the authors [JM] and states that the process nevertheless met the standards of a fair and objective review.

Copyright (C) 2016 Nikolic, Mavridis, Djikic, Vucicevic, Agbaba, Yelekci and Mitchell. This is an open-access article distributed under the terms of the Creative Commons Attribution License (CC BY). The use, distribution or reproduction in other forums is permitted, provided the original author(s) or licensor are credited and that the original publication in this journal is cited, in accordance with accepted academic practice. No use, distribution or reproduction is permitted which does not comply with these terms. 